\title{
Geoquímica das águas do médio e baixo rio Madeira e seus principais tributários - Amazonas - Brasil
}

\author{
Adriana Maria Coimbra HORBE 1 , Maria Mireide de Andrade QUEIROZ², Cândido Augusto Veloso \\ MOURA $^{3}$, Marco Antonio Galarza TORO 3
}

\section{RESUMO}

Este trabalho teve como objetivo estudar as águas do rio Madeira e seus principais tributários entre a cidade de Humaitá e sua foz no rio Amazonas. Foram analisados pH, condutividade, turbidez, íons maiores, elementos traço e isótopos de $\mathrm{Sr}$ nos períodos de seca, cheia e transição para a seca entre 2009 e 2010. As águas do Madeira, classificadas com brancas, são bicarbonatadas-cálcicas, têm pH entre 5 e 6 e são mais concentradas que as dos tributários. Estes têm águas de cor preta, mais ácidas e quimicamente heterogêneas, os da margem esquerda são quimicamente mais semelhantes as do Madeira, enquanto os da margem direita têm alta concentração em $\mathrm{SiO}_{2}$. Os cátions, $\mathrm{Cl}^{-} \mathrm{e} \mathrm{NO}_{3}^{-}$são mais concentrados na cheia o que sugere influência do solo, da vegetação e da composição da água da chuva $\left(\mathrm{Cl}^{-}\right)$, enquanto $\mathrm{HCO}_{3}^{-}, \mathrm{SO}_{4}^{2-}, \mathrm{Al}, \mathrm{Br}$ e $\mathrm{P}$, com maiores concentraçóes na seca, devem estar relacionados com a química das rochas. A $\mathrm{SiO}_{2}$ e os elementos terras raras (ETR) com concentraçóes elevadas na seca e na cheia, estão associados tanto a vegetação e ao solo como as rochas. A interação desses fatores é a causa da heterogeneidade química das águas. Contudo, a semelhança entre as águas dos tributários da margem esquerda e as do Madeira são consequência das rochas dos Andes serem a fonte dos sedimentos cenozóicos percolados por elas, enquanto a química das águas dos tributários da margem direita retrata a estabilidade tectônica, o intenso intemperismo e a baixa taxa de erosão das rochas do cráton Amazônico.

PALAVRAS-CHAVE: sazonalidade, íons maiores, elementos traços e isótopos de Sr.

\section{Chemistry of waters of the middle and lower Madeira River and its main tributaries- Amazonas - Brazil}

\begin{abstract}
The aim of this paper was study the water of the Madeira River and its tributaries, between the city of Humaitá and its confluence in the Amazon River. There were analyzed: $\mathrm{pH}$, conductivity, turbidity, major ions, trace elements and strontium isotopes during the dry and wet seasons and also, in the transition from the wet to the dry season, throughout 2009 and 2010. The white waters from the Madeira River are bicarbonated, calcic, with pH between 5 and 6 and the ions concentrations are higher than those of the tributaries. The waters of the tributaries are black, are more acidic and are chemically heterogeneous; those from the left margin are chemically similar to the waters of Madeira River, while those from the right margin are enriched in dissolved $\mathrm{SiO}_{2}$. The concentrations of cations, $\mathrm{Cl}^{-}$and $\mathrm{NO}_{3}^{-}$are higher during the wet season due to the contribution of soils, vegetation and the rainwater composition $\left(\mathrm{Cl}^{-}\right)$, while $\mathrm{HCO}_{3}^{-}, \mathrm{SO}_{4}^{2-}, \mathrm{Al}, \mathrm{Br}$ e $\mathrm{P}$ are concentrated in the dry season, and their higher contents may be related to the bedrock. The higher concentrations of $\mathrm{SiO}_{2}$ and rare earth elements in both dry and wet season are related to vegetation, soil and rocks. The interaction of these factors causes the chemical heterogeneity of the water. However, the chemical similarities between the water tributaries of the left margin and the water of the Madeira River, are probably, consequence of the Andean rocks be the sources of the Cenozoic sedimentary rocks percolated by these tributaries while the chemistry water of the tributaries of the right margin are in accordance with the tectonic stability, the intense weathering and the low erosion rate of the Amazon craton.
\end{abstract}

KEYWORDS: seasonality, major ions, trace elements and $\mathrm{Sr}$ isotopes.

\footnotetext{
1 Universidade Federal do Amazonas, UFAM, Departamento de Geociências. Av. General Rodrigo Otávio Jordão Ramos, 3000 - Japiim. CEP: 69077-000 Manaus, AM. e-mail: ahorbe@ufam.edu.br

2 Universidade Federal do Pará, UFPA, Instituto de Geociências, Programa de Pós-Graduação. Rua Augusto Correia, 1 - Guamá. CEP: 66075-110 Belém, PA. e-mail: mireide_queiroz@yahoo.com.br

${ }^{3}$ Universidade Federal do Pará, Instituto de Geociências. Rua Augusto Correia, 1 - Guamá. CEP: 66075-110 Belém, PA. e-mail: candido@ufpa.br e antogt@ufpa.br
} 


\section{INTRODUÇÃO}

O rio Madeira, afluente do rio Amazonas com aproximadamente $1.450 \mathrm{~km}$ de extensão, corta a porção sudoeste e noroeste dos estados do Amazonas e Rondônia. Tem nascente na Bolívia, a partir da confluência dos rios Guaporé, Mamoré, Beni e Madre de Dios e é identificado como de água branca devido à grande carga de sedimentos em suspensão (Sioli 1968). Ao longo do seu curso recebe diversos afluentes (Abunã, Jaci-Paraná, Candeias do Jamari, Machado, Marmelos, Manicoré, Aripuanã, Canumã, Madeirinha e Acará). Suas águas escoam sobre rochas da cordilheira dos Andes, do cráton Amazônico e da bacia do Amazonas e, ao longo das suas margens desenvolvem-se vastas planícies aluviais formadas a partir da deposição de sedimentos carreados pelas águas.

Rios como o Madeira, com centenas de quilômetros de extensão, os quais se estruturam ao longo de unidades geológicas distintas e que atuam como os principais agentes de transporte dos produtos de erosão continental para os oceanos, são ideais para entender como ocorrem os processos de interaçáo rocha-água nos continentes e a área fonte dos sedimentos nas bacias de drenagem. Essa interaçáo é influenciada por vários fatores, que incluem: 1) composição das rochas e taxa de intemperismo na bacia de drenagem; 2) atividades antropogênicas; 3) aportes eólicos, glaciais e da precipitação que interagem com os aerossóis da atmosfera e a vegetação (Goldstein e Jacobsen 1988, Gaillardet et al. 1997). Contudo, outros fatores também influenciam a água dos rios, pois ela é composta por uma fração dissolvida, mais ligada ao clima e influenciada pela precipitaçáo, vazão e temperatura, e outra particulada que depende do relevo, da atividade tectônica e da área da bacia (Canfield 1997). Desse modo a relação entre essas fraçôes também dá informaçôes sobre a mobilidade dos elementos, a intensidade do intemperismo físico e químico das rochas, permite calcular o coeficiente de partição dos elementos entre a fase dissolvida e particulada auxiliando, assim a identificar as influências do ambiente (Dupré et al. 1996, Gaillardetet al. 1997, Moquet et al. 2011).

Alguns trabalhos nessa linha de estudo já foram realizados na Amazônia nos rios Solimóes e Amazonas (Edmond et al. 1995, Mortatti e Probst 2003, Tardy et al. 2005 e outras referências por eles citadas). Estes estudos indicam que nos rios com elevada carga de material em suspensão (água branca) o pH é próximo ao neutro, $\mathrm{HCO}_{3}-\mathrm{Ca}^{2+}$ e $\mathrm{Mg}^{2+}$ são os íons mais concentrados e entre os elementos traços destacam-se $\mathrm{Ba}, \mathrm{Cu}, \mathrm{Mo}, \mathrm{Mn} \mathrm{Ni}, \mathrm{Rb} \mathrm{Sr}, \mathrm{U}, \mathrm{V}$, e $\mathrm{Zn}$, enquanto os rios com elevada quantidade de matéria orgânica (água preta) têm pouco sedimento em suspenção, baixo $\mathrm{pH}(4,0$ to 6,0$) \mathrm{e} \mathrm{Na}^{+}$, $\mathrm{K}^{+}, \mathrm{SiO}_{2}, \mathrm{Fe}, \mathrm{Al}, \mathrm{Mn}$ são os constituintes mais concentrados. Contudo, comparativamente a outros rios como o Congo, Mississipi e Orinoco os rios da Amazônia são mais diluídos.
Mortatti e Probst (2003) estimaram que o rio Amazonas transporta $148,9 \times 10^{6}$ ton ano ${ }^{-1}$ de material dissolvido e que a atmosfera contribui com $57 \%$ do $\mathrm{SO}_{4}^{2-}, 22 \%$ do $\mathrm{Cl}, 6 \%$ do $\mathrm{Ca}, 4 \%$ de $\mathrm{Mg}, 14 \%$ de $\mathrm{Na}$ e $32 \%$ de $\mathrm{K}$ da composiçấo química da água desse rio.

Apesar de vários estudos já terem sido realizados nos grandes rios da Amazônia, a maioria utilizou apenas amostras pontuais e há poucos dados sobre os afluentes e sobre a interação rocha-água-floresta. Com o objetivo de contribuir no avanço do conhecimento sobre as influências, bem como as variaçôes ao longo do ciclo hidrológico e o aporte dos afluentes na composição química das águas dos rios da Amazônia, foi selecionado para estudo o rio Madeira e seus principais afluentes, entre a cidade de Humaitá e sua confluência com o rio Amazonas.

\section{MATERIAL E MÉTODOS}

\section{Área de Estudo}

A regiáo de estudo esta localizada no segmento do rio Madeira entre a cidade de Humaitá e sua foz no rio Amazonas que engloba os seus tributários Marmelos, Manicoré, Aripuanã, Canumã, pela margem direita, e o Acará e Madeirinha, pela margem esquerda (Figura 1). Os rios da margem direita são mais extensos, têm centenas de quilômetros de extensão, nascentes nos estados do Mato Grosso, Rondônia e sudeste do estado do Amazonas. Grande parte de seus cursos drenam as rochas do cráton Amazônico expostas a longo e intenso intemperismo. Por sua vez, os afluentes da margem esquerda têm poucas dezenas de quilômetros de extensão e estão sobre as rochas sedimentares cenozoicas e depósitos sedimentares recentes.

O clima da região é quente e úmido, com temperatura média anual entre $24-26^{\circ} \mathrm{C}$, a cobertura vegetal é de floresta densa, com árvores de grande porte. De acordo com dados pluviométricos obtidos entre 1982 e 2009 pela Agência Nacional de Águas (ANA) em Humaitá, a estaçáo de maior pluviosidade, ou de cheia, se estende de outubro a abril e a de menor pluviosidade, ou de seca, de junho a agosto. Com base nesses dados a precipitação média anual é de $1733 \mathrm{~mm}$, com máximo de $245 \mathrm{~mm}$ em março e mínima de $26 \mathrm{~mm}$ em julho. A umidade relativa do ar é, em média, de $77 \%$ na estação seca e $88 \%$ na chuvosa.

$\mathrm{O}$ rio Madeira drena três unidades morfo-estruturais principais: a cordilheira dos Andes (15\%), o craton Amazônico (41\% da bacia) e a planície Amazônica (44\%), com litologias e geomorfologia distintas (Guyot et al. 2007). Na porção da cordilheira dos Andes, onde estáo as cabeceiras do Madeira, e ao longo de grande parte do seu curso, ocorrem rochas sedimentares e sedimentos quaternários, enquanto os afluentes da margem direita provêm de rochas ígneas e 


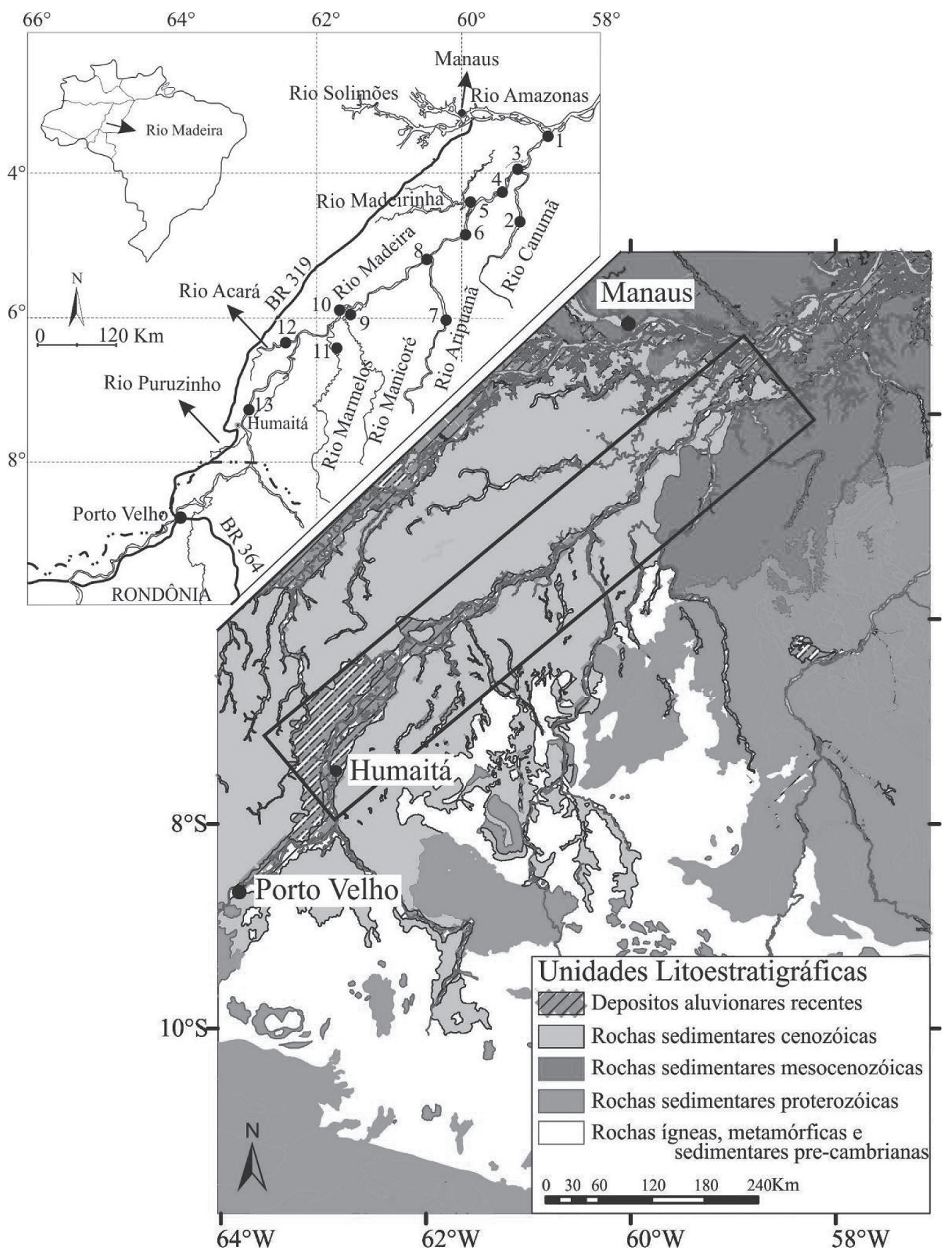

Figura 1 - Mapa de localização das amostras coletadas e mapa geológico (o retângulo no mapa geológico representa a extensão estudada do rio Madeira, 0 mapa geológico é colorido na versão eletrônica). 
(meta) sedimentares precambrianas e paleozóicas do cráton Amazônico com menor contribuição de rochas sedimentares cenozóicas (Roddaz et al. 2005 e CPRM 2006) (Figura 1).

A química das águas do rio Madeira e de seus afluentes (Canumã, Madeirinha, Aripuanã, Manicoré, Marmelos e Acará) foi determinada com base em 39 amostras coletadas em 13 pontos de amostragem. Essa amostragem abrangeu três períodos climáticos distintos, agosto de 2009 representando a estação seca com precipitaçáo média mensal de $109 \mathrm{~mm}$ mês e vazão de $6400 \mathrm{~m}^{3} \mathrm{~s}^{-1}$, fevereiro de 2010 estação de cheia com precipitação de $415 \mathrm{~mm}$ mês e vazão de $45200 \mathrm{~m}^{3} \mathrm{~s}^{-1}$ e maio de 2010 transição para seca com precipitação de $257 \mathrm{~mm}$ mês e vazão de $28400 \mathrm{~m}^{3} \mathrm{~s}^{-1}$ (Figura 1). As amostras foram retiradas aproximadamente a $15 \mathrm{~cm}$ de profundidade e filtradas com seringas plásticas acopladas a unidades filtrantes descartáveis com membrana de poros de $0,45 \mu \mathrm{m}$. Foram separadas três alíquotas de cada amostra em frascos de polipropileno de $100 \mathrm{~mL}$, previamente tratados com soluçáo de ácido nítrico $\left(\mathrm{HNO}_{3}\right)$ a $25 \%(\mathrm{v} / \mathrm{v})$, lavados com água deionizada e secos. Nas alíquotas reservadas para as determinaçôes de cátions e ânions foram adicionados aproximadamente $0,02 \mathrm{~g}$ de timol (para preservação dos íons) e nas amostras para os elementostraço e isótopos de $\mathrm{Sr}$ duas gotas ácido nítrico bidestilado.

Logo após a amostragem, uma vez que algumas características se modificam rapidamente, foram determinados $\mathrm{pH}$ e condutividade elétrica ambos por potenciometria, turbidez por turbidimetria, $\mathrm{HCO}_{3}^{-}$por titulometria com ácido sulfúrico $0,02 \mathrm{~N}$ com metil-orange como indicador. A determinação de $\mathrm{SiO}_{2}$ foi realizada por espectrofotometria (FEMTO Cirrus 80 PR, São Paulo, Brasil) no Laboratório de Química Ambiental do Instituto Nacional de Pesquisas da Amazônia (INPA). Os cátions $\left(\mathrm{Na}^{+}, \mathrm{K}^{+}, \mathrm{Mg}^{2+} \mathrm{e} \mathrm{Ca}^{2+}\right)$ e ânions $\left(\mathrm{Cl}, \mathrm{NO}_{3}^{-}, \mathrm{SO}_{4}^{2-}\right)$ foram determinados por cromatografia iônica (DIONEX ICS 900, Sunnyvale, CA, EUA) no Laboratório de Geoquímica do Departamento de Geociências da Universidade Federal do Amazonas. Para aferir-se a qualidade das análises, foram utilizados padrôes DIONEX, além de amostra de referência do INPA, que possui controle da composição química com base em certificados internacionais.

Os elementos-traço ( $\mathrm{S}, \mathrm{Al}, \mathrm{Fe}, \mathrm{P}, \mathrm{Sb}, \mathrm{Sr}, \mathrm{Ba}, \mathrm{Zn}, \mathrm{Br}, \mathrm{Mn}$, $\mathrm{Ti}, \mathrm{B}, \mathrm{Rb}, \mathrm{Cu}, \mathrm{Li}, \mathrm{Sc}, \mathrm{Ni}, \mathrm{Co}, \mathrm{Cr}, \mathrm{V}, \mathrm{As}, \mathrm{Se}, \mathrm{Pb}, \mathrm{Mo}, \mathrm{Pd}, \mathrm{Y}$, $\mathrm{Hg}, \mathrm{In}, \mathrm{Tb}, \mathrm{Tl}, \mathrm{Pt}, \mathrm{Re}, \mathrm{Rh}, \mathrm{Nb}, \mathrm{Cs}, \mathrm{Hf}, \mathrm{Zr}, \mathrm{U}, \mathrm{W}, \mathrm{Ta}, \mathrm{Ag}, \mathrm{Au}$, $\mathrm{Be}, \mathrm{Bi}, \mathrm{Cd}, \mathrm{Ga}, \mathrm{Ge}, \mathrm{Ru}, \mathrm{Sn}, \mathrm{Te}, \mathrm{Th}$ ) e os elementos terras raras (ETR: La, Ce, Pr, Nd, Sm, Eu, Gd, Dy, Ho, Er, Yb e Lu) foram analisados por ICP-MS na Acme Analytical Laboratories LTD, em Vancouver,no Canadá. A acurácia e precisão dos resultados foram aferidas com amostras-padrão utilizadas por esse laboratório comercial. Os isótopos de $\mathrm{Sr}$ foram analisados por espectrometria de massa por termoionização (Finningan MAT262, ThermoScientific, Bremen, Alemanha) no Laboratório de Geologia Isotópica do Instituto de Geociências da UFPA,
Belém, Brasil após purificação desse elemento segundo o procedimento de rotina adotado nesse laboratório (Bordalo et al. 2007)

\section{RESULTADOS}

\section{Parâmetros Físicos e Químicos}

No rio Madeira a dinâmica sazonal controla os parâmetros físico-químicos (Figura 2, Tabela 1A,). O pH e a condutividade sáo, em geral mais altos na seca (6,1 a 6,4 e 82,2 a $96 \mu \mathrm{S} \mathrm{cm}^{-1}$, respectivamente) e com pouca variação na cheia $(5,4$ a 5,7 e 20,5 a $23,6 \mu \mathrm{S} \mathrm{cm}^{-1}$, respectivamente), enquanto a turbidez é mais elevada e variável na transição para a seca (21,6 a 256,4 NTU) e menor e similar nos outros dois períodos ( 21,7 a 24 NTU na seca e 20,5 a 23,6 NTU na cheia). São exceçôes a esse comportamento o ponto 1 , com água mais condutiva na

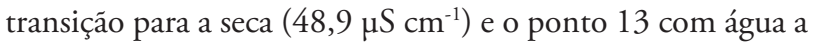
mais ácida $(4,9)$ e menos condutiva na transiçáo para a seca $\left(55 \mu \mathrm{cm}^{-1}\right)$. A turbidez nesses locais é baixa e similar na seca e na cheia (entre 22 e 23 NTU), entretanto há variação acentuada na transição para seca (entre 22 e 256 NTU) (Figura 2 e Tabela 1A). Ao longo do Madeira, apenas na seca o pH e a condutividade diminuem acentuadamente para jusante (Figura 3).

Os tributários, ao contrário do Madeira, têm águas de coloração preta, têm menor $\mathrm{pH}$ (entre 3,2 e 6), condutividade $\left(14,8\right.$ e $82,2 \mu \mathrm{S} \mathrm{cm}^{-1}$ ) e turbidez (1 e 168,5 NTU) que são, em geral mais altos na cheia e ou na transiçáo para a seca (Figura 2 e Tabela 1A). As águas do Madeirinha e do Acará, afluentes da margem esquerda do Madeira, menos ácidas e mais condutivas (5,6 e 5,1; 66,6 e $64,5 \mu \mathrm{S} \mathrm{\textrm {cm } ^ { - 1 }}$ respectivamente) que os da margem direita, são semelhantes as do Madeira na cheia e na transição para a seca (6 e 5,8; 69,1 e $82,2 \mu \mathrm{S} \mathrm{cm}^{-1}$ respectivamente). Inclusive a turbidez entre eles também é similar nos três períodos estudados (15,7 a 168,5 NTU) (Figura 2).

$\mathrm{O} \mathrm{HCO}_{3}^{-}$é o íon dominante nas águas do Madeira nos três períodos do ano (22 a $\left.38 \mathrm{mg} \mathrm{L}^{-1}\right)$, é seguido, geralmente por $\mathrm{Ca}^{2+}$ (3,5 a 10,8 $\mathrm{mg} \mathrm{L}^{-1}$ ) (Figura 2). Entre os períodos hidrológicos há variações, os teores dos cátions, assim como $\mathrm{Cl}^{-}$e $\mathrm{NO}_{3}$, são mais elevados na cheia, o que sugere maior influência da floresta que nessa época devido a enchente, a água invade as margens alagando centenas de metros, mas também da composição da água da chuva no $\mathrm{Cl}^{-}$(Gaillardet et al. 1997). $\mathrm{SiO}_{2}, \mathrm{HCO}_{3}^{-}$e $\mathrm{SO}_{4}^{2-}$ são mais elevados na seca e as menores concentraçôes estáo na transição para a seca (Figura 2). Essa variação faz com que o TDS isoladamente não represente a variação química entre os períodos hidrológicos.

As águas são mais diluídas nos tributários são, em geral ricas em $\mathrm{SiO}_{2}$, pois com o $\mathrm{pH}$ abaixo de 4,3 o $\mathrm{HCO}_{3}^{-}$está abaixo do limite de detecção. Contudo, as águas do Madeirinha, Acará 

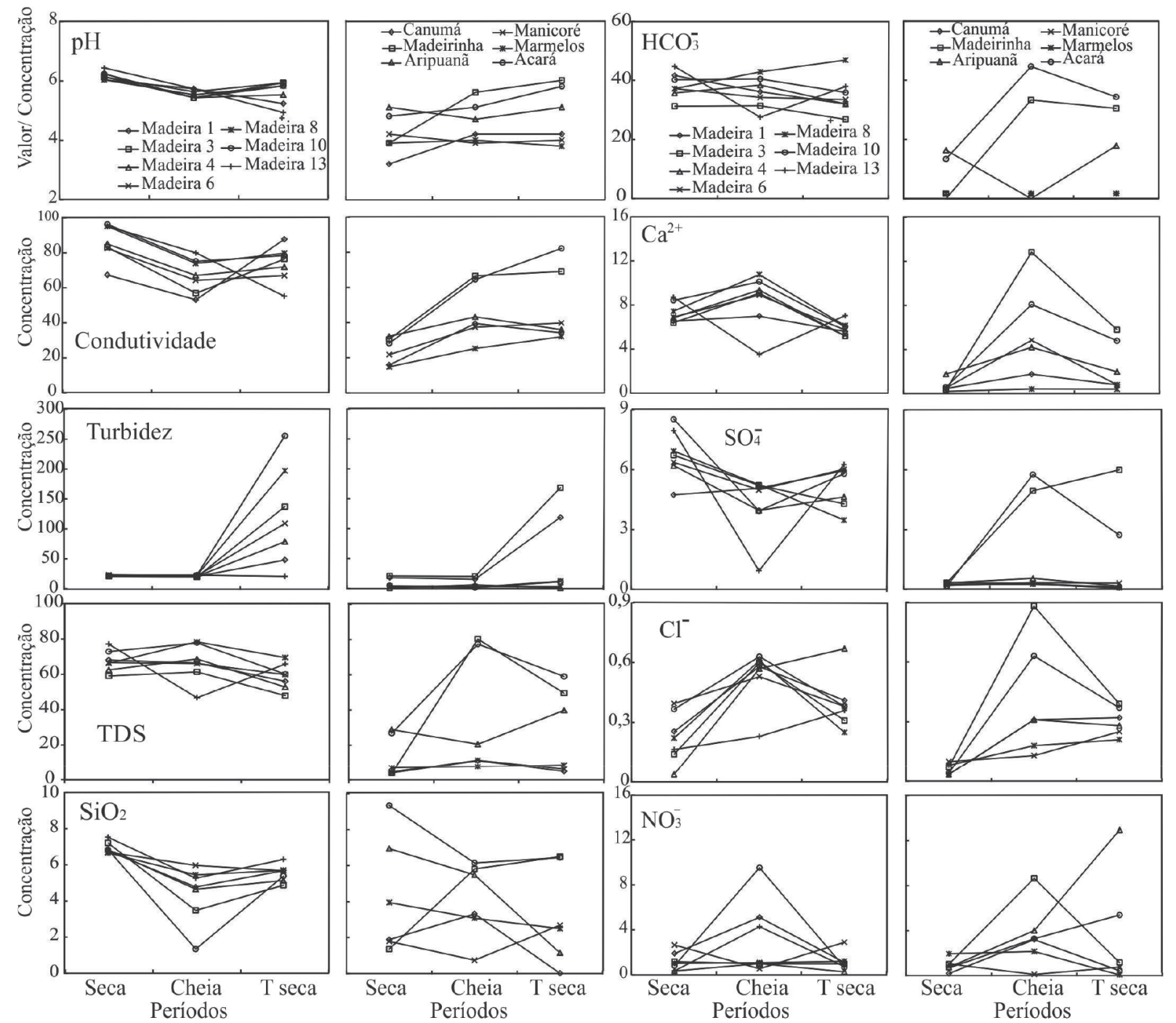

Figura 2 - Distribuição do $\mathrm{pH}$, condutividade (em $\mu \mathrm{S} \mathrm{cm}^{-1}$ ), turbidez (T, em unidade nefelométrica de turbidez - NTU), TDS (sólidos totais dissolvidos), $\mathrm{SiO}_{2}$ e dos íons (em $\mathrm{mg} \mathrm{L}^{-1}$ ) das águas segundo o período hidrológico. É apresentada somente a distribuição do Ca, pois $\mathrm{Na}, \mathrm{K}$ e Mg têm padrões similares. T seca - Transição para a seca

e Aripuaná com pH mais elevado tendem a bicarbonatadas (Figura 2 e Tabela 1A). Todos os íons estáo, em geral mais concentrados na cheia e menos na seca, exceto $\mathrm{SiO}_{2}$ com valores similares entre esses dois períodos na maioria dos rios. De todo modo o TDS isoladamente exemplifica a distribuição da carga química entre os tributários. O Madeirinha e o Acará (margem esquerda do Madeira) têm, no geral águas mais concentradas (TDS 14,2 a 74,2 $\mathrm{mg} \mathrm{L}^{-1}$ ) que as dos tributários da margem direita (Tabela 1A).

Ao longo do Madeira, apesar de haver variaçóes, a tendência é de diminuição para jusante de $\mathrm{HCO}_{3}^{-}, \mathrm{SiO}_{2}$ e dos cátions na seca e na transição para a seca (Figura 3 e Tabela 1A). Essa tendência está de acordo com a predominância de caulinita nos sedimentos em suspensão e nos acumulados nas várzeas (Martinelli et al. 1993, Guyot et al. 2007) à jusante, pois esse mineral tem baixa capacidade de reter elementos químicos por troca iônica. Mas essa tendência também está relacionada ao aporte das águas mais diluídas dos tributários. Na cheia há variaçấo acentuada na química das águas, especialmente nos pontos 1,10 e 13, o que sugere relação com o aumento da vazão e da área de inundação nessa época do ano.

A soma das cargas positivas $\left(<38 \mathrm{eq} \mathrm{L}^{-1}\right)$ classificam as águas do Madeira e dos tributários como muito diluídas $\left(\sum^{+}<185\right.$ eq L ${ }^{-1}$ Meybeck, et al. 2003) e são comparáveis a 
Tabela 1 - Concentração dos elementos traços $\left(e m \mu \mathrm{g} \mathrm{L}^{-1}\right.$ ) nas águas do rio Madeira e seus tributários (constam apenas os elementos que estão acima do limite de detecção em pelo menos uma amostra).

\begin{tabular}{|c|c|c|c|c|c|c|c|c|c|c|c|c|c|c|c|c|}
\hline & 1 & 3 & 4 & 6 & 8 & 10 & 13 & \multirow{2}{*}{ - Média } & \multirow{2}{*}{$\frac{2}{\text { Canumâ }}$} & \multirow{2}{*}{$\frac{5}{\text { Madeirinha }}$} & \multirow{2}{*}{$\begin{array}{c}7 \\
\text { Aripuanã }\end{array}$} & \multirow{3}{*}{$\begin{array}{c}9 \\
\text { Manicoré }\end{array}$} & \multirow{2}{*}{$\begin{array}{c}11 \\
\text { Marmelos }\end{array}$} & \multirow{2}{*}{$\begin{array}{c}12 \\
\text { Acará }\end{array}$} & \multirow{2}{*}{ - Média } \\
\hline & & & & & Madeir & & & & & & & & & & & \\
\hline $\mathrm{Al}$ & & 409 & 391 & 330 & - & 500 & 428 & 333 & 399 & 439 & 458 & 344 & & & 483 & 406 \\
\hline As & & 0,6 & 0,5 & 0,5 & - & 0,5 & 0,7 & 0,7 & 0,6 & $<0,5$ & $<0,5$ & $<0,5$ & $<0,5$ & $<0,5$ & 0,8 & $<0,5$ \\
\hline B & & 5 & 17 & 7 & - & 7 & 9 & 8 & 9 & $<5$ & $<5$ & $<5$ & $<5$ & $<5$ & 8 & $<6$ \\
\hline $\mathrm{Ba}$ & & 27 & 30 & 28 & - & 28 & 32 & 32 & 29 & 11 & 7,5 & 30 & 5,4 & 2,0 & 12 & 11 \\
\hline $\mathrm{Br}$ & & 14 & 19 & 16 & - & 16 & 22 & 25 & 19 & 11 & 20 & 12 & 21 & 16 & 15 & 16 \\
\hline Co & & 0,6 & 0,6 & 0,5 & - & 0,6 & 0,6 & 0,5 & 0,6 & 0,8 & 1,3 & 0,5 & 0,6 & 0,5 & 0,8 & 0,8 \\
\hline $\mathrm{Cr}$ & & 0,7 & 0,8 & $<0,5$ & - & $<0,5$ & 0,6 & $<0,5$ & 0,6 & 0,7 & 0,8 & 0,5 & 0,6 & $<0,5$ & 1,1 & 0,7 \\
\hline Cs & & 0,02 & 0,01 & 0,02 & - & 0,03 & 0,02 & 0,02 & 0,02 & 0,03 & 0,02 & 0,04 & 0,02 & 0,03 & 0,03 & 0,03 \\
\hline $\mathrm{Cu}$ & & 1,9 & 4,3 & 1,6 & - & 1,9 & 1,9 & 1,9 & 2,3 & 0,9 & 0,7 & 0,5 & 0,9 & 0,4 & 3,5 & 1,2 \\
\hline $\mathrm{Fe}$ & & 275 & 175 & 139 & - & 306 & 251 & 151 & 216 & 178 & 205 & 107 & 135 & 64 & 425 & 186 \\
\hline $\mathrm{Li}$ & & 1,5 & 1,4 & 1,5 & - & 1,5 & 2,0 & 2,1 & 1,7 & $<0,1$ & 0,6 & 0,3 & 0,3 & 0,2 & 2,8 & 0,7 \\
\hline $\mathrm{Mn}$ & & 10 & 14 & 13 & - & 26 & 6,2 & 13 & 14 & 17 & 47 & 4,5 & 22 & 3,9 & 7,0 & 17 \\
\hline Mo & & 0,2 & 0,3 & 0,3 & - & $<0,1$ & 0,3 & 0,3 & 0,3 & $<0,1$ & $<0,1$ & $<0,1$ & $<0,1$ & $<0,1$ & $<0,1$ & 0,1 \\
\hline $\mathrm{Ni}$ & & 0,8 & 1,9 & 0,5 & - & 0,6 & 0,6 & 0,6 & 0,8 & 0,7 & 1,0 & 0,5 & 0,6 & 0,4 & 2,0 & 0,9 \\
\hline P & & 83 & 66 & 68 & - & 60 & 92 & 68 & 73 & 66 & 82 & 61 & 47 & 42 & 80 & 63 \\
\hline $\mathrm{Pb}$ & & 0,4 & 1,2 & 0,3 & - & 0,3 & 0,3 & 0,5 & 0,5 & 0,2 & 0,2 & $<0,1$ & 0,3 & $<0,1$ & 1,1 & 0,3 \\
\hline $\mathrm{Rb}$ & త్ర్లో & 2,1 & 2,5 & 2,1 & - & 2,1 & 2,3 & 2,5 & 2,3 & 2,2 & 1,9 & 4,0 & 1,2 & 0,8 & 3,3 & 2,2 \\
\hline $\mathrm{Sr}$ & & 43 & 44 & 45 & - & 50 & 56 & 57 & 49 & 5,9 & 6,0 & 14 & 4,9 & 2,8 & 9,3 & 7,2 \\
\hline $\mathrm{Tl}$ & & 0,01 & 0,01 & 0,01 & - & 0,02 & 0,02 & 0,01 & 0,01 & 0,01 & 0,01 & 0,03 & $<0,01$ & $<0,01$ & 0,02 & 0,02 \\
\hline U & & 0,03 & 0,02 & 0,03 & - & 0,04 & 0,03 & 0,03 & 0,03 & $<0,02$ & $<0,02$ & $<0,02$ & $<0,02$ & $<0,02$ & $<0,02$ & $<0,02$ \\
\hline V & & 0,7 & 0,6 & 0,7 & - & 0,9 & 0,9 & 0,8 & 0,8 & 0,4 & 0,4 & 0,5 & 0,3 & 0,2 & 0,7 & 0,4 \\
\hline $\mathrm{Zn}$ & & 13 & 55 & 14 & - & 13 & 15 & 19 & 21 & 24 & 20 & 2,9 & 22 & 16 & 28 & 19 \\
\hline $\mathrm{Zr}$ & & 0,02 & 0,02 & $<0,02$ & - & 0,03 & $<0,02$ & $<0,02$ & 0,02 & 0,03 & 0,03 & $<0,02$ & 0,04 & $<0,02$ & $<0,02$ & 0,03 \\
\hline Y & & 0,17 & 0,11 & 0,09 & - & 0,23 & 0,15 & 0,10 & 0,14 & 0,05 & 0,10 & 0,10 & 0,09 & 0,04 & 0,11 & 0,08 \\
\hline$\Sigma$ & & 961 & 853 & 717 & - & 1044 & 1049 & 741 & 895 & 801 & 904 & 630 & 676 & 520 & 1247 & 797 \\
\hline La & & 0,08 & 0,10 & 0,04 & - & 0,13 & 0,06 & 0,05 & 0,08 & 0,03 & 0,03 & 0,07 & 0,06 & 0,02 & 0,04 & 0,04 \\
\hline $\mathrm{Ce}$ & & 0,24 & 0,18 & 0,14 & - & 0,36 & 0,22 & 0,13 & 0,21 & 0,09 & 0,15 & 0,15 & 0,19 & 0,10 & 0,16 & 0,14 \\
\hline Pr & & 0,03 & 0,02 & 0,02 & - & 0,05 & 0,03 & 0,02 & 0,03 & $<0,01$ & 0,02 & 0,02 & 0,02 & 0,01 & 0,02 & 0,02 \\
\hline $\mathrm{Nd}$ & & 0,16 & 0,10 & 0,10 & - & 0,24 & 0,14 & 0,10 & 0,14 & 0,05 & 0,10 & 0,10 & 0,09 & 0,04 & 0,10 & 0,08 \\
\hline $\mathrm{Sm}$ & & 0,05 & 0,03 & 0,02 & - & 0,07 & 0,03 & 0,02 & 0,04 & $<0,02$ & 0,03 & 0,02 & 0,02 & $<0,02$ & 0,03 & 0,03 \\
\hline Gd & & 0,04 & 0,03 & 0,02 & - & 0,08 & 0,04 & 0,02 & 0,04 & $<0,01$ & 0,03 & 0,02 & 0,02 & $<0,01$ & 0,03 & 0,03 \\
\hline Dy & & 0,03 & 0,02 & 0,02 & - & 0,04 & 0,03 & 0,01 & 0,03 & $<0,01$ & 0,02 & 0,01 & 0,01 & $<0,01$ & 0,02 & 0,02 \\
\hline$\Sigma$ & & 0,63 & 0,48 & 0,36 & - & 0,97 & 0,55 & 0,35 & 0,56 & 0,17 & 0,38 & 0,37 & 0,41 & 0,17 & 0,40 & 0,32 \\
\hline Al & & 35 & 53 & 26 & 34 & 29 & 33 & 25 & 34 & 55 & 22 & 57 & 146 & 113 & 30 & 71 \\
\hline As & & 0,8 & 0,8 & 0,6 & 0,5 & 0,5 & 0,6 & 0,6 & 0,6 & $<0,5$ & $<0,5$ & $<0,5$ & $<0,5$ & $<0,5$ & 2,2 & $<0,5$ \\
\hline B & & 5 & 5 & 5 & 5 & 6 & 6 & 7 & 6 & $<5$ & $<5$ & $<5$ & $<5$ & $<5$ & $<5$ & $<5$ \\
\hline $\mathrm{Ba}$ & & 23 & 22 & 21 & 22 & 22 & 21 & 23 & 22 & 4,7 & 9,7 & 18 & 7,4 & 4,2 & 23 & 11 \\
\hline $\mathrm{Br}$ & & 7 & 7 & 5 & 6 & 6 & 5 & 6 & 6 & $<5$ & $<5$ & $<5$ & 7 & $<5$ & $<5$ & $<5$ \\
\hline Co & & 0,22 & 0,20 & 0,13 & 0,12 & 0,08 & 0,15 & 0,07 & 0,14 & 0,05 & 0,08 & 0,05 & 0,13 & 0,06 & 0,23 & 0,10 \\
\hline $\mathrm{Cu}$ & 离 & 4,0 & 3,5 & 2,7 & 2,8 & 2,6 & 3,2 & 3,1 & 3,1 & 0,4 & 1,6 & 0,7 & 2,1 & 0,6 & 1,5 & 1,2 \\
\hline $\mathrm{Fe}$ & & 182 & 210 & 125 & 163 & 135 & 148 & 199 & 166 & 63 & 101 & 154 & 176 & 90 & 94 & 113 \\
\hline $\mathrm{Li}$ & & 1,3 & 1,3 & 1,4 & 1,4 & 1,3 & 1,5 & 1,6 & 1,4 & $<0,1$ & 0,6 & 0,2 & 0,2 & 0,2 & 2,0 & 0,6 \\
\hline $\mathrm{Mn}$ & & 60 & 55 & 35 & 41 & 22 & 35 & 14 & 37 & 05 & 21 & 5 & 12 & 4 & 56 & 17 \\
\hline Mo & & 0,2 & 0,2 & 0,2 & 0,2 & 0,2 & 0,2 & 0,2 & 0,2 & $<0,1$ & $<0,1$ & $<0,1$ & $<0,1$ & $<0,1$ & $<0,1$ & $<0,1$ \\
\hline $\mathrm{Ni}$ & & 1,4 & 0,7 & 0,9 & 0,7 & 0,6 & 0,8 & 0,8 & 0,8 & 0,2 & 0,7 & 1,3 & 0,4 & 0,3 & 0,9 & 0,6 \\
\hline $\mathrm{Pb}$ & & 0,8 & 0,3 & 0,4 & 0,3 & 0,2 & 0,2 & 0,2 & 0,3 & $<0,1$ & 0,7 & 0,4 & 0,2 & 0,1 & 0,1 & 0,3 \\
\hline
\end{tabular}


Tabela 1 - Continuação

\begin{tabular}{|c|c|c|c|c|c|c|c|c|c|c|c|c|c|c|c|c|}
\hline & 1 & 3 & 4 & 6 & 8 & 10 & 13 & \multirow{2}{*}{ - Média } & 2 & 5 & 7 & 9 & 11 & 12 & \multirow{2}{*}{ Média } \\
\hline & & \multicolumn{7}{|c|}{ Madeira } & & Canumã & Madeirinha & Aripuanã & Manicoré & Marmelos & Acará & \\
\hline $\mathrm{Rb}$ & \multirow{17}{*}{$\frac{\frac{\pi}{0}}{\frac{0}{0}}$} & 1,8 & 1,7 & 1,9 & 1,9 & 1,8 & 1,7 & 1,9 & 1,8 & 0,6 & 0,9 & 2,2 & 1,0 & 1,1 & 3,1 & 1,5 \\
\hline $\mathrm{Sr}$ & & 27 & 25 & 26 & 26 & 26 & 28 & 31 & 27 & 0,6 & 13 & 4,5 & 2,4 & 0,7 & 26 & 7,8 \\
\hline U & & 0,05 & 0,03 & 0,06 & 0,05 & 0,05 & 0,05 & 0,05 & 0,05 & $<0,02$ & 0,03 & 0,04 & 0,03 & 0,05 & 0,04 & 0,04 \\
\hline V & & 0,5 & 0,5 & 0,3 & 0,3 & 0,3 & 0,3 & 0,3 & 0,4 & $<0,2$ & $<0,2$ & $<0,2$ & $<0,2$ & $<0,2$ & $<0,2$ & $<0,2$ \\
\hline $\mathrm{Zn}$ & & 62 & 99 & 97 & 97 & 99 & 80 & 75 & 87 & 43 & 57 & 61 & 83 & 66 & 78 & 65 \\
\hline $\mathrm{Zr}$ & & 0,03 & 0,03 & 0,07 & 0,04 & 0,04 & 0,04 & 0,04 & 0,04 & 0,06 & 0,03 & 0,11 & 0,13 & 0,08 & 0,07 & 0,08 \\
\hline$Y$ & & 0,21 & 0,21 & 0,16 & 0,19 & 0,16 & 0,17 & 0,17 & 0,18 & 0,07 & 0,09 & 0,41 & 0,25 & 0,28 & 0,15 & 0,21 \\
\hline$\Sigma$ & & 413 & 485 & 349 & 401 & 353 & 365 & 389 & 394 & 184 & 238 & 316 & 445 & 291 & 327 & 300 \\
\hline $\mathrm{La}$ & & 0,09 & 0,09 & 0,08 & 0,09 & 0,09 & 0,08 & 0,08 & 0,09 & 0,08 & 0,05 & 0,37 & 0,19 & 0,25 & 0,04 & 0,16 \\
\hline $\mathrm{Ce}$ & & 0,30 & 0,30 & 0,21 & 0,28 & 0,25 & 0,23 & 0,23 & 0,26 & 0,22 & 0,14 & 1,00 & 0,69 & 0,87 & 0,15 & 0,51 \\
\hline $\mathrm{Pr}$ & & 0,03 & 0,04 & 0,03 & 0,03 & 0,03 & 0,03 & 0,03 & 0,03 & 0,02 & 0,02 & 0,10 & 0,06 & 0,07 & 0,02 & 0,05 \\
\hline $\mathrm{Nd}$ & & 0,18 & 0,17 & 0,12 & 0,15 & 0,15 & 0,13 & 0,15 & 0,15 & 0,08 & 0,07 & 0,43 & 0,29 & 0,32 & 0,09 & 0,21 \\
\hline $\mathrm{Sm}$ & & 0,04 & 0,05 & 0,03 & 0,05 & 0,03 & 0,04 & 0,04 & 0,04 & $<0,02$ & 0,02 & 0,07 & 0,05 & 0,05 & 0,02 & 0,04 \\
\hline $\mathrm{Gd}$ & & 0,05 & 0,05 & 0,04 & 0,05 & 0,04 & 0,05 & 0,06 & 0,05 & 0,02 & 0,03 & 0,06 & 0,05 & 0,05 & 0,07 & 0,05 \\
\hline Dy & & 0,03 & 0,03 & 0,02 & 0,03 & 0,02 & 0,03 & 0,03 & 0,03 & $<0,01$ & 0,01 & 0,06 & 0,04 & 0,04 & 0,03 & 0,04 \\
\hline $\mathrm{Er}$ & & 0,01 & 0,01 & $<0,01$ & 0,01 & $<0,01$ & 0,01 & 0,01 & 0,01 & $<0,01$ & $<0,01$ & 0,03 & 0,02 & 0,02 & 0,01 & 0,02 \\
\hline$\Sigma$ & & 0,73 & 0,74 & 0,53 & 0,69 & 0,61 & 0,60 & 0,63 & 0,65 & 0,42 & 0,34 & 2,12 & 1,39 & 1,67 & 0,43 & 1,06 \\
\hline $\mathrm{Al}$ & & 163 & 149 & 193 & 151 & 206 & 155 & 157 & 168 & 136 & - & 174 & 150 & 172 & 118 & 150 \\
\hline As & & 0,6 & 0,6 & 0,6 & 0,8 & 0,5 & 0,6 & 0,5 & 0,6 & 0,7 & - & 0,7 & 0,5 & 1,3 & 0,7 & 0,8 \\
\hline B & & 9 & 8 & 9 & 10 & $<5$ & 9 & $<5$ & 8 & 12 & - & 15 & $<5$ & 9 & 14 & 11 \\
\hline $\mathrm{Ba}$ & & 33 & 33 & 32 & 30 & 14 & 31 & 35 & 30 & 30 & - & 33 & 9 & 23 & 34 & 26 \\
\hline Co & & 0,2 & 0,1 & 0,1 & 0,2 & 0,2 & 0,1 & 0,1 & 0,1 & 0,1 & - & 0,1 & 0,1 & 0,5 & 0,2 & 0,2 \\
\hline $\mathrm{Cr}$ & & 0,7 & 0,6 & 0,6 & 0,5 & 0,6 & 0,6 & 0,7 & 0,6 & $<0,5$ & - & $<0,5$ & $<0,5$ & $<0,5$ & $<0,5$ & $<0,5$ \\
\hline Cs & & 0,02 & 0,01 & 0,01 & 0,02 & 0,02 & 0,02 & 0,04 & 0,02 & 0,01 & - & 0,02 & 0,04 & 0,02 & 0,02 & 0,02 \\
\hline $\mathrm{Cu}$ & & 3,7 & 3,6 & 3,9 & 4,1 & 1,7 & 4,4 & 2,3 & 3,4 & 3,5 & - & 2,8 & 1,6 & 2,3 & 3,2 & 2,7 \\
\hline $\mathrm{Fe}$ & & 249 & 214 & 281 & 276 & 196 & 224 & 308 & 250 & 219 & - & 218 & 114 & 701 & 173 & 285 \\
\hline $\mathrm{Li}$ & & 1,4 & 1,6 & 1,4 & 1,5 & 0,3 & 1,4 & 0,6 & 1,2 & 1,5 & - & 1,8 & 0,4 & 1,4 & 1,5 & 1,3 \\
\hline $\mathrm{Mn}$ & & 17 & 15 & 17 & 16 & 10 & 17 & 4 & 14 & 20 & - & 14 & 5 & 81 & 34 & 31 \\
\hline Mo & & 0,2 & 0,2 & 0,2 & 0,2 & 0,1 & 0,2 & 0,1 & 0,2 & 0,2 & - & 0,2 & $<0,1$ & $<0,1$ & 0,2 & 0,2 \\
\hline $\mathrm{Ni}$ & & 1,0 & 0,9 & 0,8 & 0,8 & 0,3 & 1,0 & 0,4 & 0,7 & 0,9 & - & 0,9 & 0,2 & 1,1 & 0,8 & 0,8 \\
\hline$P$ & & 57 & 32 & 40 & 52 & 20 & 33 & 30 & 38 & 44 & - & 53 & 20 & 41 & 50 & 42 \\
\hline $\mathrm{Pb}$ & $\frac{\Phi}{0}$ & 0,5 & 0,4 & 0,3 & 0,7 & 0,8 & 0,6 & 0,5 & 0,5 & 0,3 & - & 0,5 & 0,3 & 0,3 & 0,2 & 0,3 \\
\hline $\mathrm{Rb}$ & $\widetilde{\widetilde{T}}$ & 2,3 & 2,1 & 2,1 & 2,1 & 1,5 & 2,2 & 3,6 & 2,3 & 2,0 & & 2,1 & 1,1 & 3,1 & 2,5 & 2,1 \\
\hline $\mathrm{Sr}$ & 2 & 32 & 34 & 31 & 31 & 2 & 31 & 11 & 25 & 33 & - & 35 & 1 & 15 & 39 & 25 \\
\hline U & . ్ָర్లి & 0,04 & $<0,02$ & 0,04 & 0,04 & 0,04 & 0,04 & 0,03 & 0,04 & $<0,04$ & - & $<0,02$ & 0,04 & 0,02 & 0,04 & 0,03 \\
\hline V & 튠 & 0,5 & 0,5 & 0,6 & 0,6 & 0,3 & 0,5 & 0,4 & 0,5 & 0,5 & - & 0,6 & $<0,2$ & 0,3 & 0,5 & 0,4 \\
\hline $\mathrm{Zn}$ & & 369 & 290 & 432 & 262 & 276 & 281 & 288 & 314 & 355 & - & 326 & 219 & 270 & 251 & 284 \\
\hline $\mathrm{Zr}$ & & 0,14 & 0,10 & 0,10 & 0,15 & 0,14 & 0,14 & 0,11 & 0,13 & 0,09 & - & 0,11 & 0,09 & 0,12 & 0,10 & 0,10 \\
\hline$Y$ & & 0,21 & 0,19 & 0,19 & 0,24 & 0,21 & 0,22 & 0,26 & 0,21 & 0,16 & - & 0,19 & 0,20 & 0,16 & 0,22 & 0,19 \\
\hline$\Sigma$ & & 938 & 784 & 1045 & 837 & 734 & 791 & 843 & 853 & 858 & - & 876 & 528 & 1322 & 721 & 857 \\
\hline $\mathrm{La}$ & & 0,15 & 0,12 & 0,14 & 0,14 & 0,18 & 0,14 & 0,24 & 0,16 & 0,11 & - & 0,13 & 0,17 & 0,11 & 0,09 & 0,12 \\
\hline $\mathrm{Ce}$ & & 0,32 & 0,28 & 0,35 & 0,33 & 0,43 & 0,3 & 0,51 & 0,36 & 0,28 & - & 0,29 & 0,51 & 0,35 & 0,21 & 0,33 \\
\hline $\mathrm{Pr}$ & & 0,04 & 0,04 & 0,05 & 0,05 & 0,04 & 0,04 & 0,06 & 0,05 & 0,03 & - & 0,04 & 0,05 & 0,04 & 0,03 & 0,04 \\
\hline $\mathrm{Nd}$ & & 0,21 & 0,18 & 0,23 & 0,19 & 0,17 & 0,18 & 0,26 & 0,2 & 0,19 & - & 0,16 & 0,17 & 0,19 & 0,14 & 0,17 \\
\hline $\mathrm{Sm}$ & & 0,06 & 0,04 & 0,07 & 0,05 & 0,04 & 0,05 & 0,05 & 0,05 & 0,04 & - & 0,05 & 0,03 & 0,05 & 0,03 & 0,04 \\
\hline $\mathrm{Gd}$ & & 0,04 & 0,04 & 0,06 & 0,06 & 0,02 & 0,06 & 0,05 & 0,05 & 0,05 & - & 0,05 & 0,02 & 0,06 & 0,02 & 0,04 \\
\hline Dy & & 0,03 & 0,04 & 0,04 & 0,05 & 0,03 & 0,04 & 0,04 & 0,04 & 0,03 & - & 0,04 & 0,02 & 0,04 & 0,03 & 0,03 \\
\hline $\mathrm{Er}$ & & 0,02 & 0,02 & 0,02 & 0,02 & 0,02 & 0,02 & 0,03 & 0,02 & 0,02 & - & 0,02 & 0,02 & 0,02 & $<0,01$ & 0,02 \\
\hline $\mathrm{Yb}$ & & 0,01 & 0,01 & 0,02 & 0,01 & 0,01 & 0,01 & 0,02 & 0,01 & 0,01 & - & $<0,01$ & $<0,01$ & 0,01 & $<0,01$ & 0,01 \\
\hline$\Sigma$ & & 0,88 & 0,77 & 0,98 & 0,90 & 0,94 & 0,84 & 1,26 & 0,94 & 0,76 & - & 0,78 & 0,99 & 0,87 & 0,55 & 0,79 \\
\hline
\end{tabular}



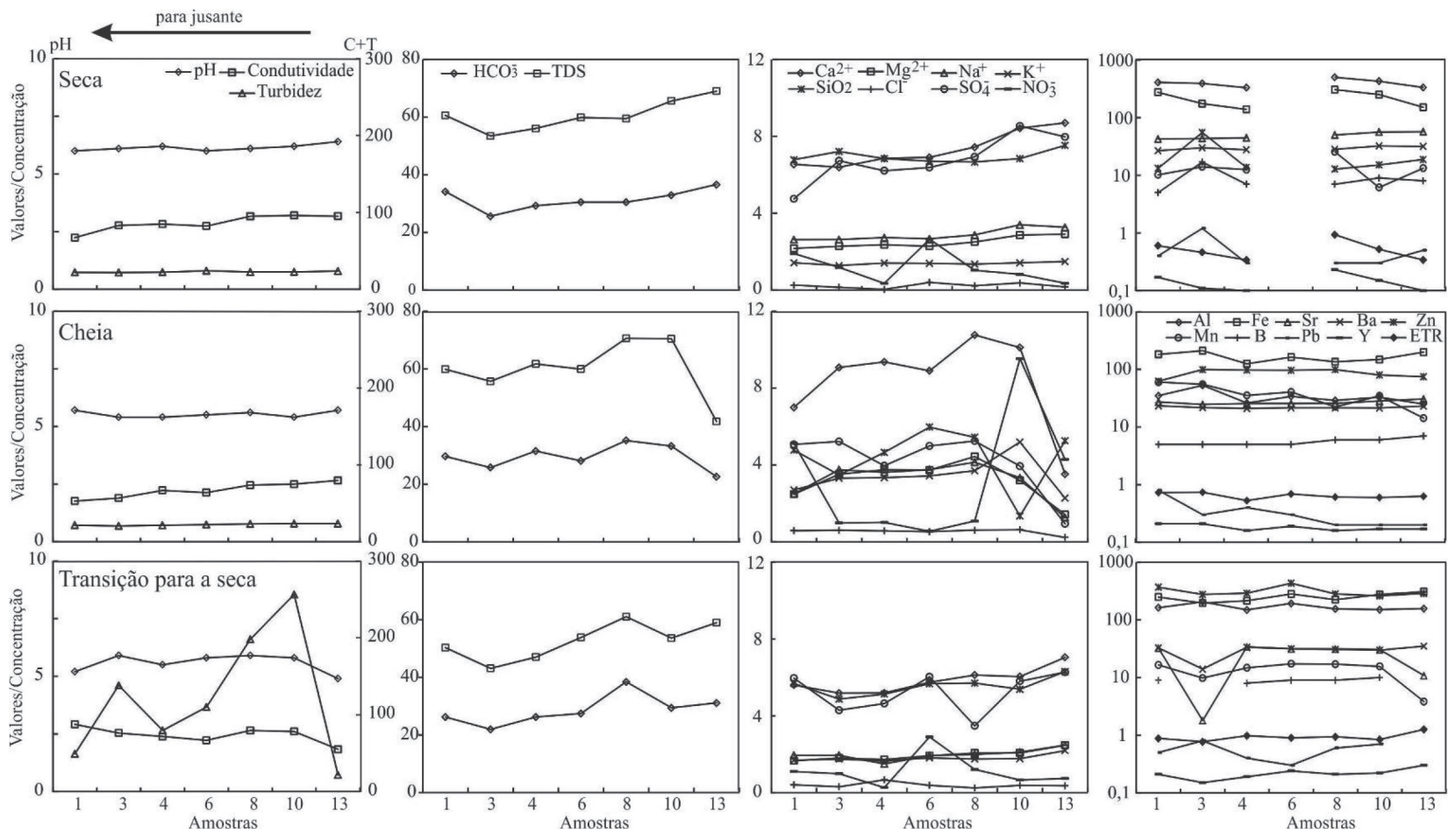

Figura 3 - Distribuição do pH, condutividade (C em $\mu \mathrm{S} \mathrm{cm}^{-1}$ ), turbidez (T em NTU), TDS (total de sólidos dissolvidos), $\mathrm{SiO}_{2}$ e íons maiores (em mg L-1) e elementos traços (em $\mu \mathrm{g} \mathrm{L}^{-1}$ ) nas água ao longo do rio Madeira segundo o período hidrológico (Amostra Madeira 6 não houve análise de elementos traços na seca)

rios semelhantes da Amazônia (Gaillardet et al. 1997, Tosiani et al. 2004 e Queiroz et al. 2009). Essa carga é inferior a rios de regióes menos chuvosas e com ausência de carbonatos e evaporitos nas bacias (Meybeck 2003), que são as principais fontes de elementos para as águas, pois são facilmente dissolvidos.

\section{Elementos-Traço}

Desses elementos, exceto os ETR que seráo discutidos a seguir, $\mathrm{Al}, \mathrm{B}, \mathrm{Ba}, \mathrm{Br}, \mathrm{Cu}, \mathrm{Fe}, \mathrm{Li}, \mathrm{Mn}, \mathrm{P}, \mathrm{Rb}, \mathrm{Sb}, \mathrm{Sr}, \mathrm{Zn}$, apresentam, em geral teores superiores a $1 \mu \mathrm{g} \mathrm{L} \mathrm{L}^{-1}$, enquanto As, Co, Cr, Cs, Mo, Ni, Pb, Se, Tl, U, V, Zr e Y estão entre 0,1 e $0,01 \mu \mathrm{g} \mathrm{L}^{-1}$ (Tabela 1). Os demais elementos (Ag, Au, Bi, $\mathrm{Be}, \mathrm{Cd}, \mathrm{Ga}, \mathrm{Ge}, \mathrm{Hf}, \mathrm{Hg}$, In, Nb, Pd, Pt, Ru, Rh, Re, Sc, Se, Sn, Ta, Tb, Te, Th, Tl e W) estão abaixo do limite de detecção do método analítico empregado.

A influência da sazonalidade também se faz notar nos elementos-traços, eles têm conteúdos similares na seca e na transiçáo para a seca e estáo mais diluídos na cheia tanto nas águas do Madeira como nas dos tributários (Tabela 1). Essa homogeneidade difere dos íons principais que possuem variação acentuada entre os períodos.

As águas do Madeira possuem maiores concentraçōes de $\mathrm{B}, \mathrm{Ba}, \mathrm{Cu}, \mathrm{Li}, \mathrm{Mo}, \mathrm{Pb}, \mathrm{Sr}, \mathrm{U}, \mathrm{V}$ e $\mathrm{Zn}$ que as dos tributários. Por sua vez, os demais elementos com concentraçóes maiores que $0,01 \mu \mathrm{g} \mathrm{L}^{-1}$ não diferenciam as drenagens (Tabela 1 ). Dentre os elementos traços analisados, apenas Al, Br, P, Sr mais concentrados na seca, Mn na cheia e Fe, Sr e Zn na transição para a seca indicam influência da sazonalidade, enquanto os outros têm concentraçôes similares entre os três períodos de coleta. As maiores concentraçóes em elementos-traços nas águas do rio Madeira ocorrem na seca em P8 $\left(\sum=1044 \mu \mathrm{g} \mathrm{L}^{-1}\right)$ e P10 $\left(\sum=1049 \mu \mathrm{g} \mathrm{L}^{-1}\right)$ em consequência dos elevados teores de $\mathrm{Al}$ e Fe e na transição para a seca em P4 $\left(\sum=1045 \mu \mathrm{g} \mathrm{L}{ }^{-1}\right)$ (Tabela 1). Ao longo do Madeira, ao contrário do observado por Seyler e Boaventura (2003) no rio Solimóes, apenas Ba e $\mathrm{Sr}$ na seca decrescem para jusante, enquanto $\mathrm{Mn}, \mathrm{Pb}$ e $\mathrm{Y}$ aumentam claramente nessa direção na cheia e há variaçóes acentuadas em B, Pb, Mn e Zn na seca e em Mn e Sr na transição para a seca (Figura 3). Essas variaçôes podem estar relacionadas ao aporte das águas dos tributários, que por serem classificadas como pretas pressupóem maior quantidade de matéria orgânica dissolvida e coloidal e condiçôes mais redutoras que podem afetar o comportamento dos elementos como o Mn conforme constatado por Aucour et al. (2003) na confluência dos rios Negro e Solimóes.

A geoquímica das águas dos tributários é mais heterogênea e são mais diluídas que as do Madeira, especialmente na cheia (Tabela 1). Al e P são mais concentrados na seca e $\mathrm{B}, \mathrm{Ba}, \mathrm{Fe}$, $\mathrm{Mn}, \mathrm{Sr}$ e Zn na transição para a seca (Tabela 1). Contudo, 
há tendência das águas dos tributários e do Madeira se assemelharem no conteúdo de elementos traços na transição para a estiagem, provavelmente em consequência de mistura entre suas águas que afetaram os locais de amostragem, mas esse fato necessita ser investigado. A semelhança com as águas do Madeira também é observada nos rios Madeirinha e Acará na seca e no rio Manicoré na cheia (Tabela 1).

Entre os elementos terras raras (ETR), Ce e $\mathrm{Nd}$ são os mais abundantes (de 0,04 a 0,87 $\mu \mathrm{g} \mathrm{L}^{-1}$ ), seguidos de La, $\mathrm{Pr}$, Sm, Gd, Dy, Er, $\mathrm{Yb}\left(\mathrm{de}<0,01\right.$ a $\left.0,37 \mu \mathrm{g} \mathrm{L}^{-1}\right)$, enquanto $\mathrm{Tb}$, Ho, Tm e Lu estáo em concentraçóes inferiores a $0,01 \mu \mathrm{g} \mathrm{L} \mathrm{L}^{-1}$ (Tabela 1). A somatória da concentraçấo dos ETR nas águas do rio Madeira é mais elevada na transição para a seca $(0,77$ a $\left.1,26 \mu \mathrm{g} \mathrm{L}^{-1}\right)$ e menor na seca $(0,35$ a $0,97 \mu \mathrm{g} \mathrm{L}-1)$, exceto no P3 (a montante do Canumã) com concentraçóes similares na cheia $\left(0,74 \mu \mathrm{g} \mathrm{L}^{-1}\right)$ e na transição para a seca $\left(0,77 \mu \mathrm{g} \mathrm{L} \mathrm{L}^{-1}\right) \mathrm{e}$ no P8, a montante do Aripuaná menos concentrada na cheia $\left(0,61 \mu \mathrm{g} \mathrm{L}{ }^{-1}\right)$ e similar nos outros dois períodos $\left(0,97 \mu \mathrm{gL}^{-1}\right.$ na seca e $0,94 \mu \mathrm{L} \mathrm{L}^{-1}$ na transição para a seca). Essa tendência dos ETR, menos concentrados na seca, difere dos demais elementos-traço com concentraçóes menores na cheia (Tabela 1). Ao longo do Madeira a variação dos ETR é irregular (Tabela 1, Figura 3).

Nos tributários há variação no conteúdo total dos ETR. As águas do Aripuanã, Manicoré e Marmelos são mais concentradas na cheia $\left(1,39\right.$ a $\left.2,12 \mu \mathrm{g} \mathrm{L} \mathrm{L}^{-1}\right)$, enquanto as do Canumã e Acará acompanham as do Madeira ou seja são mais elevadas na transiçáo para a seca $\left(0,76\right.$ e $0,55 \mu \mathrm{g} \mathrm{L}^{-1}$ respectivamente), mas todas, exceto as águas do Acará, com concentraçóes similares na seca e cheia, também são mais diluídas na seca $(0,17$ a $0,41 \mu \mathrm{g} \mathrm{L}-1)$ (Tabela 1$)$. As águas do Madeirinha, analisadas apenas na seca e na transição para a seca, são homogêneas no conteúdo total de ETR nesses dois períodos (0,38 e $0,34 \mu \mathrm{g} \mathrm{L} \mathrm{L}^{-1}$, respectivamente). Shiller (1997), Goldstein e Jacobsen (1988) e Tosiani et al. (2004) encontraram correlação negativa entre La e pH em águas de rios, entretanto essa relaçáo náo ocorre quando se comparam as águas do Madeira com as dos tributários (Tabela 1).

\section{Isótopos de Estrôncio}

As razóes ${ }^{87} \mathrm{Sr} /{ }^{86} \mathrm{Sr}$ foram obtidas nas águas do rio Madeira e apenas nas águas dos rios Aripuanã na seca e Acará, na cheia e na transição para a seca (Tabela 1A) devido a baixa concentração de Sr nas águas (Tabela 1). As águas do rio Madeira na seca são, em geral, menos radiogênicas $\left({ }^{87} \mathrm{Sr} /{ }^{86} \mathrm{~S} r 0,71681\right.$ e 0,71816$)$ o que coincide com a época em que os elementos-traço estão em sua maior concentração. $\mathrm{Na}$ cheia do rio Madeira os valores da razão ${ }^{87} \mathrm{Sr} /{ }^{86} \mathrm{Sr}$ tiveram a maior oscilação (entre 0,71793 e 0,72327 ) e na transição para a seca a menor (entre 0,71920 e 0,72042 ). Ao longo do rio Madeira as águas tendem a serem mais radiogênicas para jusante na seca e na cheia (de 0,71681 para 0,71816 e
0,71898 para 0,72327 , respectivamente) e o inverso ocorre na transição para a seca $(0,72042$ e 0,71989). A água do Aripuanã na seca foi a mais radiogênica de todas $(0,73556)$, enquanto as do Acará săo as menos radiogênicas na cheia $(0,71674) \mathrm{e}$ na transição para a seca $(0,71779)$.

\section{DISCUSSÃO}

As características químicas descritas acima são muito bem ilustradas na análise de agrupamento (Figura 4) que utilizou a média da composição química dos períodos hidrológicos ponderada pela precipitação para minimizar o efeito da sazonalidade. Apesar das águas dos tributários serem quimicamente heterogêneas, nota-se que as dos tributários da margem direita (Marmelos, Canumá, Manicoré e Aripuanã) e a do Madeirinha da margem esquerda formam um grupo quimicamente distinto das águas do Madeira as quais se correlacionam com as do Acará (Figura 4A). A semelhança química entre as águas do Madeira e as do Acará é maior que entre os demais tributários. Mas ambos os grupos apresentam forte correlação entre os elementos traços, incluindo os ETR, $\mathrm{pH}$, turbidez e $\mathrm{Cl}^{-}$o que indica que esses elementos exercem pouca influência na caracterizaçáo das águas. A associaçáo entre os demais íons, apesar da correlação menos acentuada entre eles, são os que separam os grupos, de modo que as associaçôes entre $\mathrm{SiO}_{2}-\mathrm{SO}_{4}^{2-}, \mathrm{NO}_{3}^{-}-\mathrm{K}^{+}-\mathrm{Na}^{+}-\mathrm{Mg}^{2+}$ e Ca ${ }^{2+}$ com menor correlação (Figura 4B) qualificam as águas do Madeira, enquanto o $\mathrm{SO}_{4}^{2-}$ ao se correlacionar com $\mathrm{K}^{+}-\mathrm{Na}^{+}-\mathrm{Mg}^{2+} \mathrm{e}$ $\mathrm{NO}_{3}-\mathrm{SiO}_{2}-\mathrm{Ca}^{2+}$ qualificam as águas dos tributários (Figura 4C). TDS e $\mathrm{HCO}_{3}^{-}$tem baixa correlação tanto nas águas do Madeira como nas dos tributários. Normalmente o Fe e Al na fraçáo inferior a $0,45 \mu \mathrm{m}$ constituem os coloides minerais que proveem da caulinita e dos óxi-hidróxidos de Fe dos solos, e os coloides orgânicos (Dupré et al. 1999, Tang e Johannesson 2003 e Nystrand et al. 2012). Portanto, a associação do Al e Fe com os demais elementos traços sugere que grande parte da concentração desses elementos pode estar como colóide, enquanto os íons maiores devem estar realmente dissolvidos na água ( $>0,2 \mu \mathrm{m})$ como observado por Dupré et al. (1999), Tang e Johannesson (2003) e Nystrand et al. (2012) nas águas dos rios.

A influência da sazonalidade na química das águas, normal nos rios (Shiller 1997, Elbaz-Poulichetet al. 1999, Smolders et al. 2004), está provavelmente relacionada a dois fatores que estão interligados: 1) o efeito diluidor provocado pela água da chuva com o consequente aumento na vazão e na quantidade de água que percola pela bacia e 2) o aumento da área inundada que permite maior interação da água com a vegetação e solo. A interação água-floresta-solo, mais eficiente na época da cheia, provoca aumento na quantidade de colóides, especialmente em rios de águas ácidas (Tang e Johannesson 2003) o que afeta os processos de oxi-reduçáo, a disponibilidade e a partição dos 

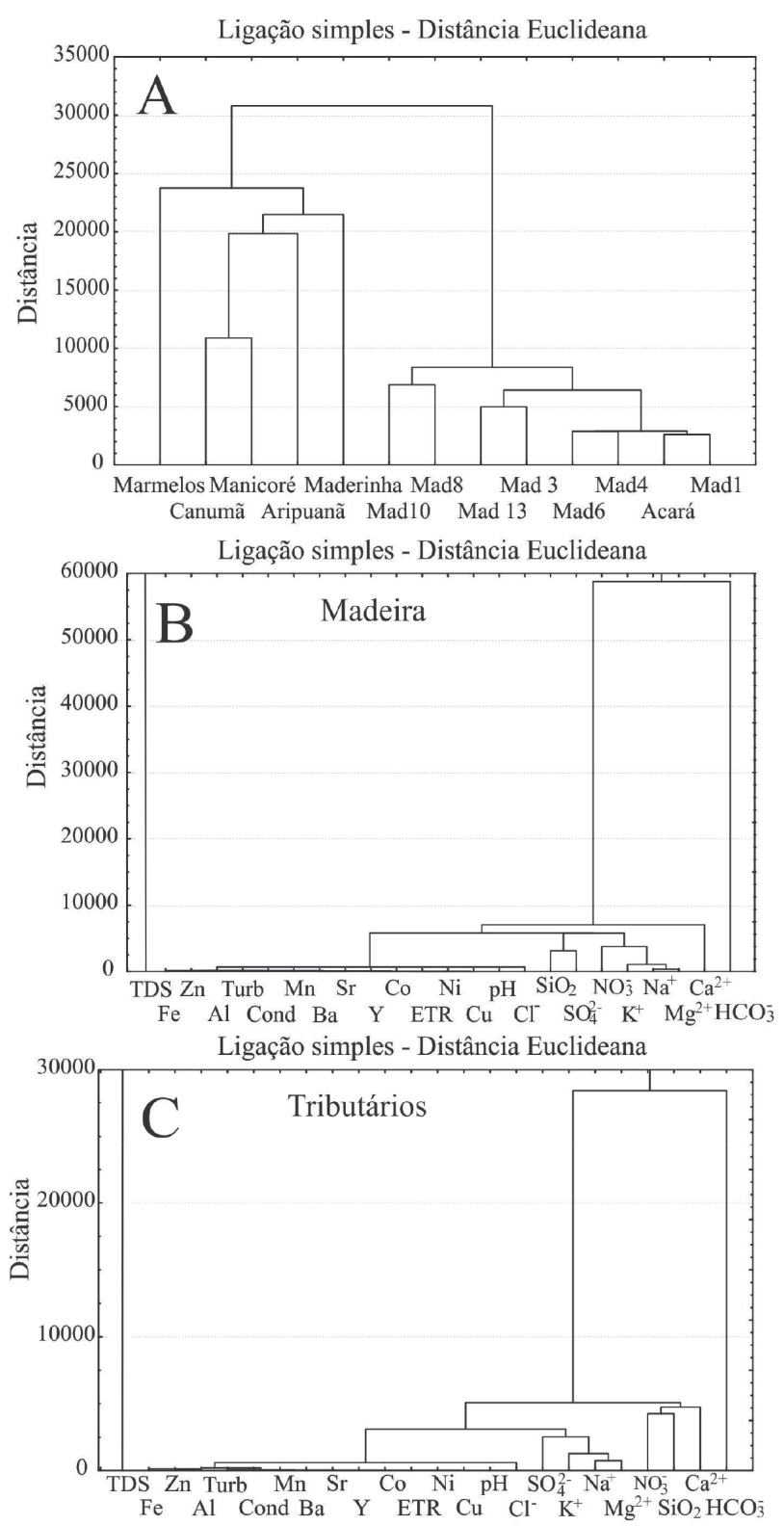

Figura 4 - Resultado da análise estatística multivariada via agrupamento: A: Grau de similaridade geoquímica entre as drenagens estudadas determinada com base nos parâmetros de pH, condutividade, turbidez, íons e os elementostraços mais abundantes; B: Identificação das associações geoquímicas que caracterizam as águas do Madeira e C: Identificação das associações geoquímicas que caracterizam as águas dos tributários (Turb: turbidez, ETR: elementos terras raras, TDS: total de sólidos dissolvidos)

elementos químicos nas fases que compõem as águas dos rios (Elderfiled et al. 1990, Shiller 1997, Viers et al. 2008). Além dos colóides, as poeiras terrestres e biogênicas acumuladas e emitidas pela vegetação (Artaxo et al. 2006) e arrastadas pela água da chuva ajudam a aumentar a concentração em elementos dissolvidos na água (Honório et al. 2010) apesar do efeito diluidor provocado pelo aumento na intensidade da chuva e na velocidade de percolaçáo. Portanto, as águas mais concentradas nos íons principais, exceto $\mathrm{SO}_{4}^{2-}$ mais elevado na seca nas águas do Madeira, devem estar relacionadas à influência da floresta e do solo. Por outro lado, as rochas, via água acumulada no solo e no lençol freático, parecem ser a principal fonte do $\mathrm{SO}_{4}^{2-}$ e dos elementos traços, pois eles têm tendência a maior concentração na transiçấo para a seca e na seca, tanto nas águas do Madeira com nas dos tributários. $\mathrm{A} \mathrm{SiO}_{2}$ e os ETR parecem ter contribuição tanto das rochas como da floresta e do solo já que eles têm concentraçôes similares na seca e na cheia. Essa ampla variedade de fatores influenciando a química das águas justifica a heterogeneidade no comportamento dos elementos, retrata a complexa química aquática e torna difícil determinar as causas das variaçôes e dos fatores que determinam a composição química das águas.

\section{Características Geoquímicas do Ambiente Percolado}

No intuito de identificar diferenças no ambiente geoquímico percolado pelas águas, foi calculado o fracionamento dos elementos traço em relação à média crustal (Taylor e McLennan 1985). Os Andes tectonicamente instáveis e constituídos basicamente por rochas sedimentares e vulcânicas facilmente intemperizadas e erodidas, o cráton Amazônico com terrenos granito-gnaisse com baixa taxa de erosão e intenso intemperismo e a planície Amazônica com rochas sedimentares cenozoicas e sedimentos formados por contribuição de ambos - Roddaz et al. 2005 e CPRM 2006) indicam ambientes geológicos distintos. Como constatado, esses ambientes geram águas com características físico-químicas distintas, entretanto o padrão das curvas e a intensidade de fracionamento é similar, as águas são fortemente empobrecidas em relação à crosta continental (Figuras 5 e 6). Dentre os elementos As e $\mathrm{B}$ nas águas do Madeira e Cu, Li, Mo, Sr, $\mathrm{Zn}$ tanto nestas quanto nas dos tributários, são um pouco menos empobrecidos que a crosta continental (Figura 5), o que indica que são mais facilmente lixiviados das rochas, ou seja, estáo associados a minerais mais facilmente intemperizáveis. $\mathrm{O} Z \mathrm{Zr}$ por ser o mais empobrecido e por formar, preferencialmente zircáo, mineral resistente ao intemperismo, é o que tem menor mobilidade e, portanto tende a se acumular no material de fundo dos rios. Os demais elementos têm mobilidade intermediária.

Os ETR revelam empobrecimento um pouco mais acentuado que a maioria dos demais elementos-traço, especialmente em La e Ce (Figuras 5 e 6) o que sugere que esses elementos têm menor mobilidade que os demais ETR nas rochas das bacias o que provoca sua baixa concentração nas águas. A homogeneidade no padrão das curvas de fracionamento dos ETR, assim como dos demais elementos traços nas águas do Madeira, especialmente na cheia, reflete a mesma origem. Por sua vez as águas dos tributários são 


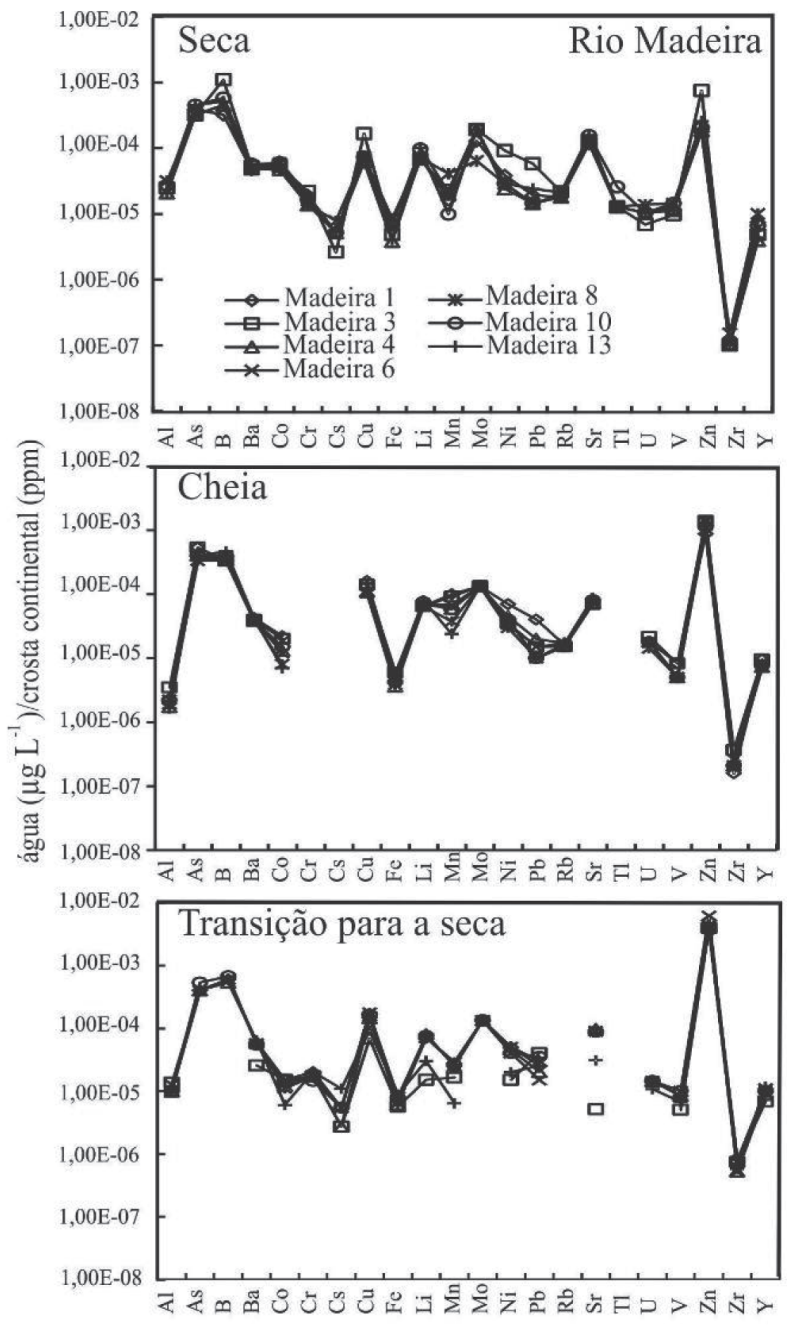

Elementos
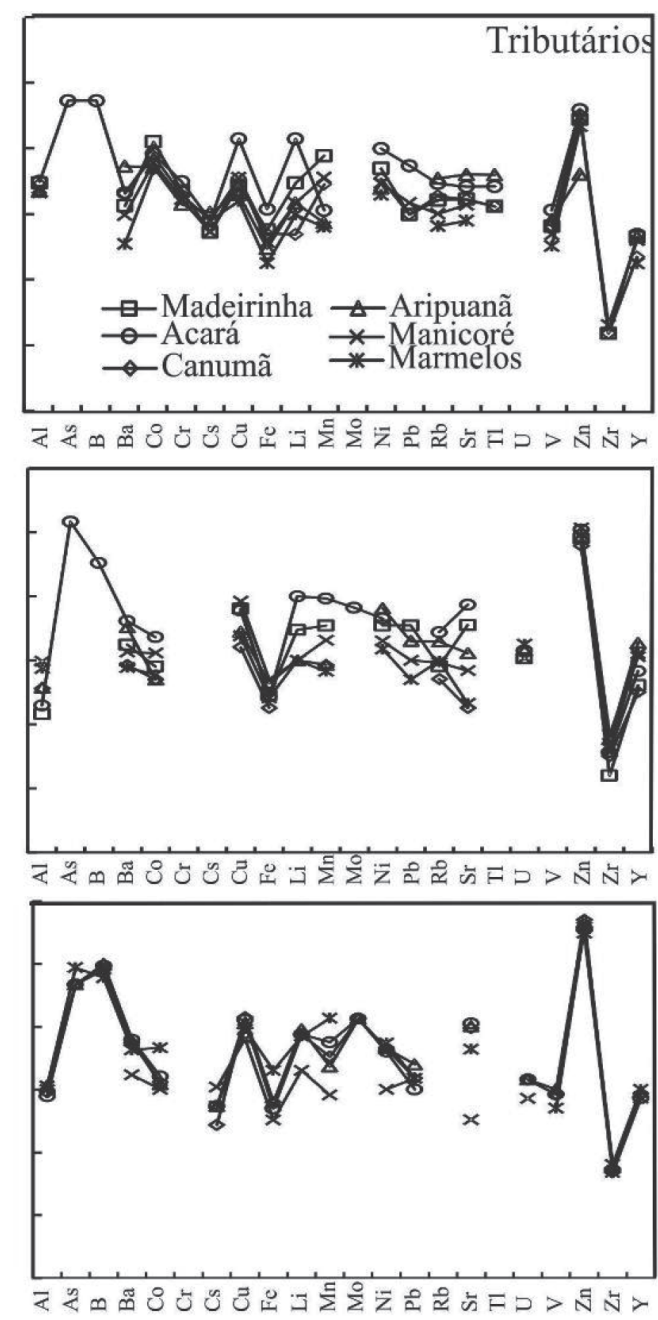

Elementos

Figura 5 - Fracionamento dos elementos-traços em relação a média da crosta continental (não foi utilizado o Br pois não há análise desse elementos para a crosta continental)

mais heterogêneas, notadamente na cheia, e um pouco mais fracionadas em relação a crosta continental que as do Madeira. A intensidade de fracionamento na cheia, época em que esses elementos estáo mais concentrados, permite separar os tributários em dois grupos: o Manicoré, Marmelos e Aripuaná com águas menos fracionadas que as do Acará, Madeirinha e Canumã (Figura 6). Isto, mais as relaçôes $\mathrm{Na}^{+}+\mathrm{K}^{+}$versus $\mathrm{SiO}_{2}$, $\mathrm{Ca}^{2+} / \mathrm{Na}^{+}+\mathrm{K}^{+}$versus $\mathrm{Mg}^{2+} / \mathrm{Na}^{+}+\mathrm{K}^{+}$e Ba versus $\mathrm{Sr}$ (Figura 7), obtidas com base na média da composição química ponderada pela pluviosidade dos três períodos climáticos estudados com o objetivo de minimizar influência da sazonalidade, reforçam a heterogeneidade química entre eles e as diferenças geoquímicas no ambiente percolado entre os tributários, principalmente entre os da margem direita (Madeirinha e Acará) em relação aos da esquerda (Marmelos, Manicoré, Aripuanã e Canumâ). Desse modo, cada tributário que constitui uma bacia em separado, tem propriedades químicas próprias. A similaridade entre as águas dos tributários da margem esquerda, especialmente as do Acará com as do Madeira devese, provavelmente ao fato deles escoarem principalmente sobre as rochas sedimentares cenozoicas e depósitos aluvionares recentes cujas fontes foram, principalmente, os Andes. As águas do Aripuanã com valores de Ba elevados, em relação aos demais tributários, sugerem influência das ocorrências de manganês (romanechita $\left(\mathrm{Ba}, \mathrm{K}, \mathrm{Mn}^{2+}, \mathrm{Co}\right){ }_{2} \mathrm{Mn}_{5} \mathrm{O}_{10} \cdot \mathrm{nH}_{2} \mathrm{O}$ ) ao longo do seu curso (Silva et al. 2012). O Mn não acompanha o Ba, pois quando do intemperismo da romanechita ele tende a precipitar rapidamente como óxi-hidróxido arrastando consigo o Co liberado da romanechita o que diminui a mobilidade de ambos, enquanto o $\mathrm{Ba}$ tende a formar oxiânions com $\mathrm{HCO}_{3}^{-}$e $\mathrm{SO}_{4}^{2-}$ (Kabata-Pendias e Pendias 1987) e permanece dissolvido na água. 

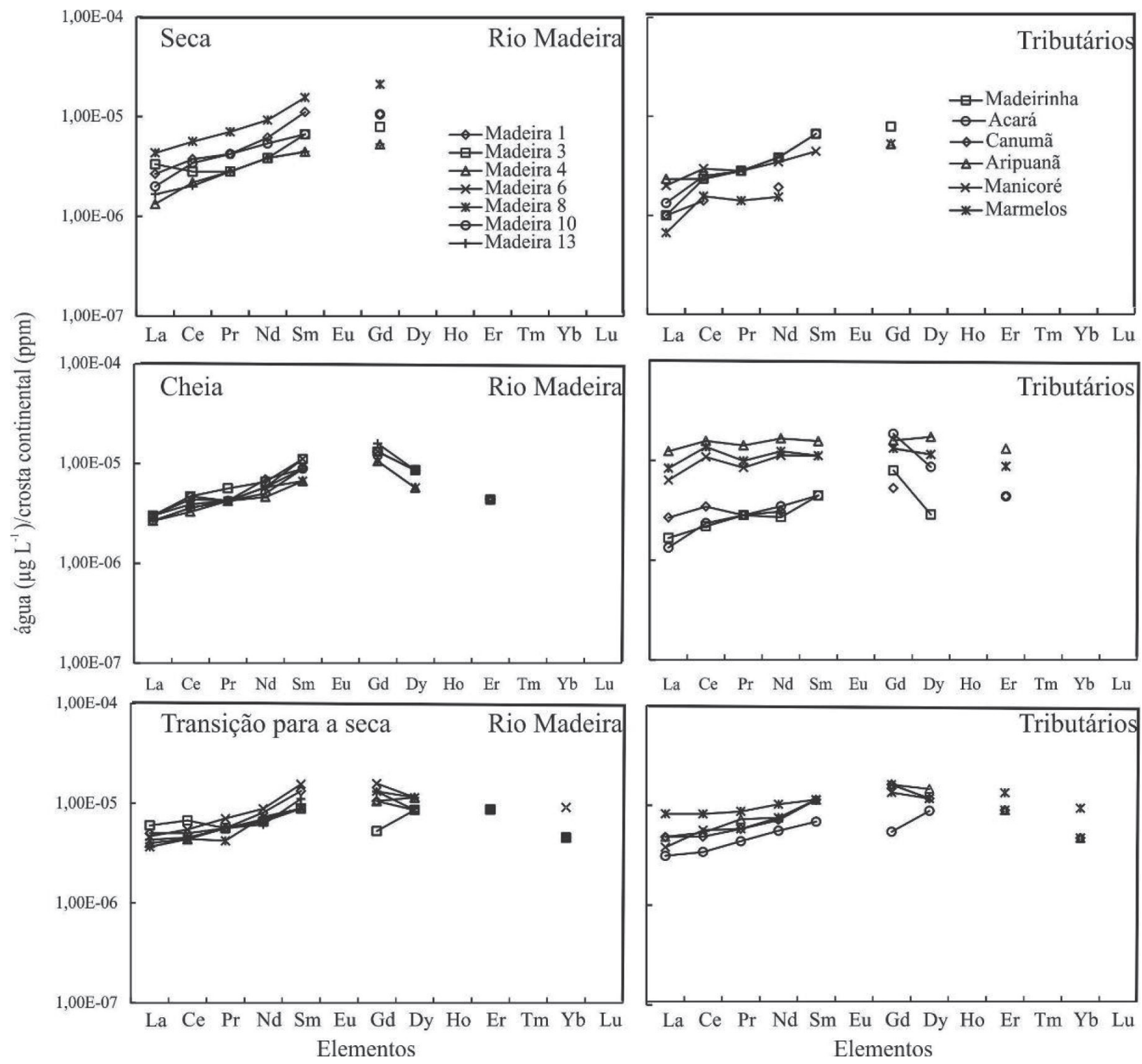

Figura 6 - Fracionamento dos ETR em relação à média da crosta continental.

Outro modo de caracterizar o ambiente percolado é por meio das razōes isotópicas ${ }^{87} \mathrm{Sr} /{ }^{86} \mathrm{Sr}$. Os valores da razão ${ }^{87} \mathrm{Sr} /{ }^{86} \mathrm{Sr}$ obtidos são mais radiogênicos que aqueles das águas dos rios Solimões e Amazonas e que as de alguns de seus tributários (Gaillardet et al. 1997 e Queiroz et al. 2009). Por sua vez, o valor da razão ${ }^{87} \mathrm{Sr} /{ }^{86} \mathrm{Sr}$ para a água do Aripuanã aproxima-se do das águas dos rios Tapajós e Tocantins que percolam também rochas do craton Amazônico (Figura 7) (Hieronymus et al. 1993 e Allègre et al. 1996). Essas relações isotópicas reforçam a distinção do ambiente geoquímico do Madeira em relaçáo ao do Solimóes, apesar de ambos terem influência dos Andes, a similaridade entre as águas do Madeira e as do Acará e a diferença entre estas e as do Aripuanã (Figura 7) como constatado com os íons principais e $\mathrm{SiO}_{2}$. Considerando que o cráton Amazônico tem assinatura ${ }^{87} \mathrm{Sr} /{ }^{86} \mathrm{Sr}$ elevada (0,735 - Allègre et al. 1996), o que justifica a composição isotópica da água do Aripuanã, pode-se associar a tendência de aumento da razão isotópica do rio Madeira, em direção a jusante, ao aporte das águas mais radiogênicas dos tributários da margem direita. 

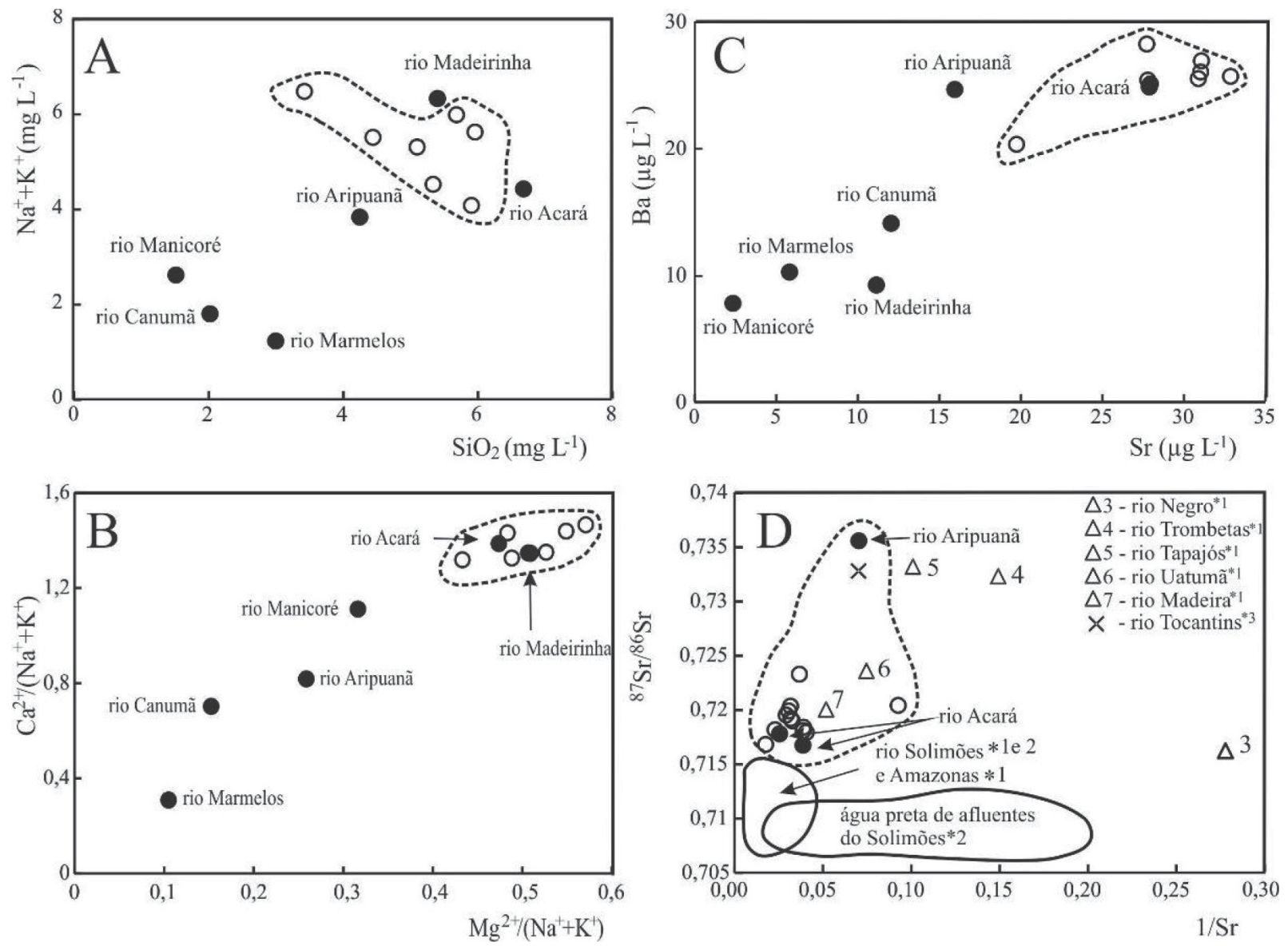

Figura 7 - $\mathrm{A}: \mathrm{Na}^{+}+\mathrm{K}^{+}$versus $\mathrm{SiO}_{2 ;} \mathrm{B}: \mathrm{Ca} /\left(\mathrm{Na}^{+}+\mathrm{K}^{+}\right)$versus $\mathrm{Mg} /\left(\mathrm{Na}^{+}+\mathrm{K}^{+}\right)$após a retirada da contribuição atmosférica; C: Ba versus $\mathrm{Sr}$ e $\mathrm{D}:{ }^{87} \mathrm{Sr} /{ }^{86} \mathrm{Sr}$ versus 1/Sr das amostras de água do Madeira (०) e dos tributários (•) (*1 amostras de Gaillardetet al. 1997; *2 de Queiroz et al. 2009 ; *3 média de Hieronymus et al. 1993). Os campos tracejados das Figuras A, B e C agrupam as águas do rio Madeira enquanto o da Figura $D$ agrupa tanto as águas do rio Madeira como as dos tributários. As razões entre os íons e do $\mathrm{SiO}_{2}$ foram obtidas com base na sua concentração em mg L $\mathrm{L}^{-1}$ e do $1 / \mathrm{Sr}$ em $\mu \mathrm{g} \mathrm{L}^{-1}$.

\section{CONCLUSÃO}

As águas brancas do Madeira são bicarbonatadascálcicas, têm pH entre 5 e 6 e são mais concentradas que as dos tributários. Estes, por sua vez, têm águas mais ácidas e quimicamente são heterogêneas, tanto entre si como em relação as águas do rio Madeira. Os da margem esquerda são semelhantes as águas do Madeira, enquanto os da margem direita são as mais concentradas em $\mathrm{SiO}_{2}$ o que indica influência do ambiente geológico.

A sazonalidade afeta de modo distinto a geoquímica das águas, entretanto há tendência das águas dos tributários e as do Madeira se assemelharem no conteúdo de elementos traços na transiçáo para a estiagem. Dois fatores provocam essa sazonalidade: 1) o efeito diluidor da água da chuva que aumenta a vazão e 2) o aumento da área inundada, que promove maior interação entre a água do rio, a vegetação, o solo e a composição da água da chuva. Contudo, é possível que os cátions, $\mathrm{Cl}^{-} \mathrm{NO}_{3}^{-}$, por serem mais concentrados na cheia, tenham relaçáo com a vegetação e o solo, por sua vez $\mathrm{HCO}_{3}^{-}$, $\mathrm{SO}_{4}^{2-}, \mathrm{Al}, \mathrm{Br}$ e $\mathrm{P}$ mais elevados na seca estáo mais relacionados com as rochas, enquanto a $\mathrm{SiO}_{2}$ com concentraçôes elevadas na seca e na cheia, está relacionada com as rochas, mas com possível influência da vegetação. Desse modo, os Andes, em consequência da intensa erosão, especialmente física, tornam as águas mais concentradas e com teores mais elevados em $\mathrm{B}, \mathrm{Ba}, \mathrm{Cu}, \mathrm{Li}, \mathrm{Mo}, \mathrm{Pb}, \mathrm{Sr}, \mathrm{U}, \mathrm{V}$ e Zn. A regiáo cratônica, com rochas expostas a longo processo intempérico, geram águas mais diluídas, mas mais concentradas em $\mathrm{SiO}_{2}$, enquanto as rochas sedimentares cenozoicas e depósitos aluvionares recentes da planície de inundação fornecem águas quimicamente similares as do Madeira. 


\section{AGRADECIMENTOS}

Os autores agradecem à Universidade Federal do Amazonas, à Universidade Federal do Pará e ao Instituto Nacional de Pesquisa na Amazônia pelo apoio logístico e laboratorial e ao Conselho Nacional de Desenvolvimento Científico e Tecnológico (CNPq) pela bolsa de doutorado da segunda autora e de produtividade aos demais autores e aos projetos 620039/2008-6 e 471971/2010-3 pelo apoio financeiro. Agradecem também aos revisores e ao editor pelas sugestóes.

\section{BIBLIOGRAFIA CITADA}

Allégre, C.J.; Dupré, B.; Négrel, P.; Gaillardet, J. 1996. Sr-Nd$\mathrm{Pb}$ isotopes systematics in Amazon and Congo river systems: Constraints about erosion processes. Chemical Geology, 131: 93-112.

ANA, 2008. Agência Nacional de Àguas. Disponível em: <http:// mapas-hidro.ana.gov.br/Usuario/DadoPesquisar.aspx. Acesso em: 5 de julho de 2008

Artaxo, P.; Oliveira, P.H.; Lara, L.L.; Pauliquevis, T.M.; Rizzo, L.V.; Pires Jr., C.; Paixão, M.A.; Longo, K.M. Freitas, S.; Correia, A.L. 2006. Efeitos climáticos de partículas de aerossóis biogênicos emitidos em queimadas na Amazônia. Revista Brasileira de Meteorologia, 21: 1-22.

Aucour, A. M.; Tao, F.X.; Moreira-Turcq, P.; Seyler, P.; Sheppard, S.; Benedetti, M.F. 2003. The Amazon River: behavior of metals $(\mathrm{Fe}, \mathrm{Al}, \mathrm{Mn})$ and dissolved organic matter in the initial mixing at the Rio Negro/Solimóes confluence. Chemical Geology, 197: 271-285.

Bordalo, A.O.; Moura, C.A.V.; Scheller, T. 2007. Determinaçấo da composiçáo isotópica de estrôncio em águas naturais: exemplos de sua aplicação em águas subsuperficiais da zona costeira na região Bragantina-PA. Química Nova, 30: 821-827.

Canfield, E. D. 1997. The geochemistry of river particulates from the continental USA: Major elements. Geochimica et Cosmochimica Acta, 61:3349-3365.

Companhia de Pesquisas e Recursos Minerais CPRM. 2006. Mapa geológico do Estado do Amazonas. Sistema de informaçôes Geográficas - SIG, Programa Geologia do Brasil, Escala 1:1.000.000. Ministério de Minas e Energia. Rio de Janeiro em CD-ROM.

Dupré, B.; Gaillardet, J.; Rousseau, D.; Allégre, J. 1996. Major and trace elements of river-borne material: The Congo Basin. Geochimica et Cosmochimica Acta, 60:1301-1321.

Edmond, J.M; Palmer, M.R; Measures, C.I; Stallard, R.F. 1995. The fluvial geochemistry and denudation rate of the Guayana Shield in Venezuela, Colombia and Brazil. Geochimica et Cosmochimica Acta, 59: 3301-3325.

Elbaz-Poulichet, F.; Seyler, P.; Maurice-Bourgoin, L.; Guyot, J.L.; Dupré, C. 1999. Trace element geochemistry in the upper Amazon drainage basin (Bolivia). Mineralogical Magazine, 62: $418-423$.
Elderfield, H.; Upstill-Goddard, R.; Sholkovitz, E.R. 1990. The rare earth elements in rivers, estuaries, and coastal seas and their significance to the composition of ocean waters. Geochemical et Cosmochemical Acta, 54 : 971-991.

Gaillardet, J; Dupré, B; Allegre. J, C; Negrel, P. 1997. Chemical and physical denudation in the Amazon river Basin. Chemical Geology, 142: 141-173,

Guyot, J.L.; Jouanneau, J.M.; Soares, L.; Boaventura, G.R.; Maillet, N.; Lagane, C. 2007. Clay mineral composition of river sediments in the Amazon Basin. Catena, 71: 340-356.

Goldstein, S.J.; Jacobsen, S.B., 1988: $\mathrm{Nd}$ and Sr isotopic systematics of river water suspended material: Implications for crustal evolution. Earth and Planetary Sciences Letters, 87, 249-265.

Hieronymus, B.; Godot, J.M.; Boulegué, J.; Bariac, T.; Negrel, P.; Dupré, B.1993. Chimie du fleuve Tocantins et de revieres cotieres de l'est du Para (Brésil). Grands Bassins Fluviaux, Paris, 357-374.

Honório, B; Horbe, A. M. C. Seyler, P. 2010. Chemical composition of rainwater in Western Amazonia-Brazil. Atmospheric Research, 98: 416-425.

Kabata-Pendias, A.; Pendias, H. 1987. Trace elements in soils and plants, CRC Press. Boca Raton, USA. 238 p.

Martinelli, L.; Victoria, R.L.; Dematte, J.L.I.; Richey, J.E.; Devol, A.H. 1993. Chemical and mineralogical composition of Amazon River floodplain sediments, Brazil. Applied Geochemistry, 8, 391-402.

Meybeck, M. 2003. Global occurrence of major elements in rivers. Treatise of Geochemistry vol 5, 207-223.

Moquet, J-S., Crave, A., Viers, J., Seyler, P., Armijos, E., Bourrel, L., Chavarri, E., Lagane, C., Laraque, A., Casimiro, W.S.L., Pombosa, R., Noriega, L., Vera, A., Guyot, J-L. 2011. Chemical weathering and atmospheric/soil $\mathrm{CO}_{2}$ uptake in the Andean and foreland Amazon basins. Chemical Geology, 287: 1-26.

Mortatti, J.; Probst, J. L. 2003. Silicate rock weathering and atmospheric/soil $\mathrm{CO}_{2}$ uptake in the Amazon Basin estimated from river water geochemistry: seasonal and spatial variations. Chemical Geology, 197, 177-196.

Nystrand, M.I.; Österholm, P; Nyberg, M.E.; Gustafsson, J.P. 2012. Metal speciation in rivers affected by enhanced soil erosion and acidity. Applied Geochemistry, 27, 906-916.

Queiroz, M.M; Horbe, A.M.C; Seyler, P; Moura A, C. A. V. 2009. Hidroquímica do rio Solimôes entre Manacapuru e Alvarães Amazonas - Brazil. Acta Amazonica, 39: 941-950.

Roddaz, M.; Viers, J.; Brusset, S.; Baby, P.; Herail, G. 2005. Sediment provenances and drainage evolution of the Neogene Amazonian foreland basin. Earth and Planetary Science Letters, 239: 57-78.

Seyler, P.; Boaventura, G. R. 2003. Distribution and partition of trace metals in the Amazon Basin. Hydrological Processes, 17, 1345-1361.

Shiller, A.M. 1997. Dissolved trace elements in the Mississippi river: Seasonal, interannaual, and decadal variability. Geochimica et Cosmochimica Acta, 61, 4321-4330.

Sioli, H. 1968. Hydrochemistry and geology in the Brazilian Amazon region. Amazoniana, 3:267-277. 


\section{ACTA}

Silva, P.J.M.; Horbe, A.M.C.; Horbe, M.A. 2012. Mineralogia e geoquímica de ocorrências manganesíferas da bacia Alto Tapajós, sudeste do estado do Amazonas, Brasil. Boletim do Museu Paraense Emilio Goeldi, 7: 11-28.

Smolders, A.J.P., Hudson-Edwards, K.A., Van der Velde, G., Roelofs, J.G.M. 2004. Controls on water chemistry of Pilcomayo river (Bolivia, South-America). Applied Geochemistry, 19: 1745-1758.

Tang J. and Johannesson K. H. 2003. Speciation of rare earth elements in natural terrestrial waters: Assessing the role of dissolved organic matter from the modeling approach. Geochimica et Cosmochimica Acta, 67, 2321-2339

Tardy, Y.; Bustillo, V.; Roquin, C.; Mortatti, J.; Victoria, R. 2005. The Amazon Biogeochemistry applied to river basin management. Part I. Hidroclimatology, hidrograph separation, mass transfer balances, stable isotopes, and modelling. Applied Geochemistry, 20, 1746-1829
Taylor, S. R.; McLennan, S.M. 1985. The Continental Crust: Its Composition and Evolution. Blackwell, Oxford, $312 \mathrm{p}$

Tosiani, T.; Loubet, M.; Viers, J.; Valladon, M.; Marrero, S.; Yanes, C.; Ramirez, A. Dupré, B. 2004. Major and trace elements in river-borne materials from the Cuyuni basin (southern Venezuela): evidence for organo-colloidal control on dissolved load and element redistribution between the suspended and dissolved load. Chemical Geology, 211: 305-334.

Viers, J.; Roddaz, M.; Filizola, N.; Guyot, J-L.; Sondag, F.; Brunet, P.; Zouiten, C.; Boucayrand, C.; Marton, F.; Boaventura, G.R. 2008. Seasonal and provenance controls on $\mathrm{Nd}-\mathrm{Sr}$ isotopic compositions of Amazon rivers suspended sediments and implications for $\mathrm{Nd}$ and $\mathrm{Sr}$ fluxes exported to the Atlantic Ocean. Earth and Planetary Science Letters, 274, 511-523.

Recebido em: 22/04/2012

Aceito em: 03/01/2013 


\section{APÊNDICE}

Tabela $1 \mathrm{~A}$ - pH, condutividade elétrica (em $\mu \mathrm{S} \mathrm{cm}^{-1}$ ), turbidez (Turb em NTU), íons principais (em mg L-1), somatória de cátions e ânions (em meq L-1) e razões ${ }^{87} \mathrm{Sr} /{ }^{86} \mathrm{Sr}$ (a partir de $\mu \mathrm{g} \mathrm{L}^{-1}$ ) nas águas do rio Madeira e seus tributários. Os dados desta tabela correspondem aos das Figuras 2 , 3 e 7D.

\begin{tabular}{|c|c|c|c|c|c|c|c|c|c|c|c|c|c|c|c|c|}
\hline & 1 & 3 & 4 & 6 & 8 & 10 & 13 & \multirow{2}{*}{ Média } & 2 & 5 & 7 & 9 & 11 & 12 & \multirow{2}{*}{ Média } \\
\hline & & \multicolumn{7}{|c|}{ Madeira } & & \multicolumn{2}{|r|}{ Madeirinha } & Aripuanã & Manicoré & Marmelos & Acará & \\
\hline$\overline{\mathrm{pH}}$ & \multirow{16}{*}{$\begin{array}{l}\text { ఝूँ } \\
\text { ભ }\end{array}$} & 6,0 & 6,1 & 6,2 & 6,0 & 6,1 & 6,2 & 6,4 & 6,1 & 3,2 & 3,9 & 5,1 & 4,2 & 3,9 & 4,8 & 4,2 \\
\hline EC & & 67 & 83 & 85 & 82 & 95 & 96 & 95 & 86 & 16 & 31 & 32 & 22 & 15 & 28 & 41 \\
\hline Turb & & 22 & 22 & 22 & 24 & 22 & 23 & 24 & 23 & 1,0 & 19 & 3,2 & 4,2 & 4,9 & 21 & 12 \\
\hline $\mathrm{Ca}^{2+}$ & & 6,54 & 6,39 & 6,85 & 6,90 & 7,44 & 8,43 & 8,70 & 7,32 & 0,46 & 0,37 & 1,77 & 0,51 & 0,20 & 0,58 & 0,65 \\
\hline $\mathrm{Mg}^{2+}$ & & 2,17 & 2,28 & 2,36 & 2,28 & 2,50 & 2,86 & 2,91 & 2,48 & 0,26 & 0,17 & 0,64 & 0,23 & 0,10 & 0,44 & 0,31 \\
\hline $\mathrm{Na}^{+}$ & & 2,62 & 2,63 & 2,73 & 2,67 & 2,87 & 3,39 & 3,27 & 2,88 & 0,26 & 0,14 & 0,92 & 0,34 & 0,17 & 0,99 & 0,47 \\
\hline $\mathrm{K}^{+}$ & & 1,42 & 1,27 & 1,40 & 1,39 & 1,35 & 1,42 & 1,49 & 1,39 & 0,62 & 0,39 & 1,12 & 0,36 & 0,32 & 1,11 & 0,65 \\
\hline $\mathrm{SiO}_{2}$ & & 6,78 & 7,21 & 6,84 & 6,70 & 6,66 & 6,84 & 7,53 & 6,94 & 1,88 & 1,36 & 6,95 & 1,79 & 3,95 & 9,34 & 4,21 \\
\hline $\mathrm{HCO}_{3}^{-}$ & & 41,68 & 31,26 & 35,72 & 37,21 & 37,21 & 40,19 & 44,66 & 38,27 & $<0,10$ & $<0,10$ & 16,37 & $<0,10$ & $<0,10$ & 13,40 & 4,96 \\
\hline $\mathrm{Cl}^{-}$ & & 0,26 & 0,14 & 0,04 & 0,40 & 0,22 & 0,37 & 0,16 & 0,23 & 0,03 & 0,07 & 0,03 & 0,10 & 0,08 & 0,04 & 0,06 \\
\hline $\mathrm{SO}_{4}^{2-}$ & & 4,74 & 6,73 & 6,21 & 6,38 & 6,94 & 8,53 & 7,97 & 6,78 & 0,34 & 0,32 & 0,32 & 0,17 & 0,24 & 0,15 & 0,25 \\
\hline $\mathrm{NO}_{3}^{-}$ & & 1,90 & 1,18 & 0,34 & 2,65 & 1,03 & 0,82 & 0,35 & 1,18 & 0,20 & 1,03 & 0,75 & 1,05 & 1,95 & 0,70 & 0,95 \\
\hline TDS & & 68,10 & 59,07 & 62,49 & 66,56 & 66,21 & 72,83 & 77,04 & 67,47 & 4,05 & 3,85 & 28,87 & 4,54 & 7,00 & 26,74 & 12,51 \\
\hline$\Sigma^{+}$ & & 21.46 & 21.23 & 22.55 & 22.42 & 24.10 & 27.38 & 27.97 & 23.87 & 2.33 & 1.61 & 6.85 & 2.18 & 1.08 & 4.15 & 3.03 \\
\hline$\Sigma$ & & 46.19 & 39.84 & 42.40 & 44.37 & 44.54 & 49.05 & 52.43 & 45.55 & 12.04 & 10.36 & 20.75 & 8.26 & 11.67 & 20.55 & 13.94 \\
\hline${ }^{87} \mathrm{Sr} /{ }^{16} \mathrm{Sr}$ & & - & 0.718161 & - & - & - & 0.716813 & - & - & - & - & 0.735561 & - & - & - & - \\
\hline$\overline{\mathrm{pH}}$ & \multirow{16}{*}{$\frac{\frac{\pi}{0}}{\frac{0}{U}}$} & 5,7 & 5,4 & 5,4 & 5,5 & 5,6 & 5,4 & 5,7 & 5,5 & 4,2 & 5,6 & 4,7 & 3,9 & 4,0 & 5,1 & 4,5 \\
\hline EC & & 53 & 57 & 67 & 64 & 74 & 74 & 80 & 67 & 39 & 67 & 43 & 37 & 25 & 64 & 53 \\
\hline Turb & & 21 & 20 & 21 & 22 & 23 & 23 & 23 & 22 & 6,5 & 6 & 2,5 & 3,5 & 1,7 & 21 & 12 \\
\hline $\mathrm{Ca}^{2+}$ & & 6,99 & 9,07 & 9,36 & 8,90 & 10,76 & 10,11 & 3,52 & 8,39 & 1,76 & 12,83 & 4,20 & 4,84 & 0,41 & 8,09 & 5,36 \\
\hline $\mathrm{Mg}^{2+}$ & & 2,48 & 3,52 & 3,75 & 3,73 & 4,44 & 3,20 & 1,42 & 3,22 & 0,28 & 4,36 & 1,33 & 1,32 & 0,14 & 2,95 & 1,73 \\
\hline $\mathrm{Na}^{+}$ & & 2,50 & 3,75 & 3,61 & 3,76 & 4,14 & 3,33 & 1,26 & 3,19 & 0,35 & 4,82 & 1,84 & 1,47 & 0,31 & 3,16 & 1,99 \\
\hline $\mathrm{K}^{+}$ & & 2,70 & 3,31 & 3,34 & 3,43 & 3,70 & 5,19 & 2,27 & 3,42 & 1,67 & 4,61 & 2,79 & 2,47 & 1,13 & 2,71 & 2,56 \\
\hline $\mathrm{SiO}_{2}$ & & 4,77 & 3,48 & 4,65 & 5,97 & 5,44 & 1,34 & 5,26 & 4,42 & 3,32 & 5,81 & 5,48 & 0,74 & 3,08 & 6,15 & 4,10 \\
\hline $\mathrm{HCO}_{3}^{-}$ & & 36,17 & 31,42 & 38,41 & 34,25 & 42,88 & 40,49 & 27,55 & 35,88 & $<10,0$ & 33,35 & $<10,0$ & $<10,0$ & $<10,0$ & 44,66 & 13,00 \\
\hline $\mathrm{Cl}^{-}$ & & 0,58 & 0,60 & 0,57 & 0,53 & 0,61 & 0,63 & 0,23 & 0,54 & 0,31 & 0,88 & 0,31 & 0,13 & 0,18 & 0,63 & 0,41 \\
\hline $\mathrm{SO}_{4}^{2-}$ & & 5,07 & 5,22 & 3,96 & 4,99 & 5,25 & 3,94 & 0,94 & 4,20 & 0,28 & 4,93 & 0,54 & 0,32 & 0,24 & 5,74 & 2,01 \\
\hline $\mathrm{NO}_{3}^{-}$ & & 5,12 & 0,98 & 1,01 & 0,55 & 1,08 & 9,53 & 4,28 & 3,22 & 3,21 & 8,65 & 4,01 & 0,11 & 2,15 & 3,28 & 3,57 \\
\hline TDS & & 66,38 & 61,35 & 68,66 & 66,11 & 78,30 & 77,76 & 46,73 & 66,47 & 11,18 & 80,24 & 20,50 & 11,40 & 7,64 & 77,37 & 34,72 \\
\hline$\Sigma^{+}$ & & 24.14 & 32.24 & 33.17 & 32.45 & 38.24 & 35.14 & 13.41 & 29.83 & 6.10 & 43.81 & 15.69 & 16.26 & 2.54 & 27.95 & 18.73 \\
\hline$\Sigma$ & & 40.65 & 35.65 & 41.23 & 40.09 & 47.06 & 39.73 & 29.24 & 39.09 & 20.21 & 39.84 & 21.41 & 9.98 & 11.25 & 49.76 & 25.41 \\
\hline${ }^{87} \mathrm{Sr} /{ }^{86} \mathrm{Sr}$ & & 0.723274 & 0.717928 & 0.718410 & - & 0.718089 & - & 0.718981 & - & - & - & - & - & - & 0.716744 & - \\
\hline $\mathrm{pH}$ & \multirow{16}{*}{ 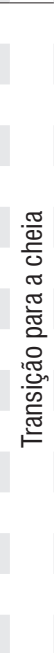 } & 5,2 & 5,9 & 5,5 & 5,8 & 5,9 & 5,8 & 4,9 & 5,6 & 4,2 & 6,0 & 5,1 & 4,0 & 3,8 & 5,8 & 4,7 \\
\hline EC & & 87 & 76 & 72 & 67 & 79 & 78 & 55 & 73 & 34 & 69 & 36 & 40 & 32 & 82 & 52 \\
\hline Turb & & 49 & 138 & 80 & 110 & 198 & 256 & 22 & 122 & 1,0 & 119 & 12 & 3,1 & 12 & 168 & 57 \\
\hline $\mathrm{Ca}^{2+}$ & & 5,60 & 5,18 & 5,19 & 5,74 & 6,12 & 6,04 & 7,04 & 5,84 & 0,79 & 5,79 & 1,98 & 0,79 & 0,40 & 4,79 & 2,42 \\
\hline $\mathrm{Mg}^{2+}$ & & 1,66 & 1,80 & 1,72 & 1,92 & 2,06 & 2,07 & 2,47 & 1,96 & 0,26 & 1,92 & 0,57 & 0,26 & 0,12 & 1,80 & 0,82 \\
\hline $\mathrm{Na}^{+}$ & & 1,94 & 1,94 & 1,50 & 1,93 & 1,99 & 2,11 & 2,48 & 1,98 & 0,85 & 1,95 & 1,28 & 0,75 & 0,68 & 1,49 & 1,17 \\
\hline $\mathrm{K}^{+}$ & & 1,69 & 1,75 & 1,65 & 1,81 & 1,75 & 1,77 & 2,19 & 1,80 & 0,97 & 1,82 & 2,02 & 0,53 & 0,51 & 1,58 & 1,24 \\
\hline $\mathrm{SiO}_{2}$ & & 5,68 & 4,87 & 5,13 & 5,67 & 5,70 & 5,38 & 6,30 & 5,53 & 1,15 & 0,02 & 2,69 & 2,50 & 6,45 & 6,50 & 3,22 \\
\hline $\mathrm{HCO}_{3}^{-}$ & & 32,00 & 26,79 & 32,00 & 33,49 & 46,90 & 35,88 & 37,95 & 35,00 & $<10,0$ & 30,51 & 17,86 & $<10,0$ & $<10,0$ & 34,39 & 13,79 \\
\hline $\mathrm{Cl}^{-}$ & & 0,41 & 0,31 & 0,67 & 0,38 & 0,25 & 0,38 & 0,36 & 0,39 & 0,32 & 0,39 & 0,28 & 0,25 & 0,21 & 0,37 & 0,30 \\
\hline $\mathrm{SO}_{4}^{2-}$ & & 5,96 & 4,29 & 4,64 & 6,03 & 3,48 & 5,80 & 6,27 & 5,21 & 0,10 & 5,98 & 0,16 & 0,30 & 0,05 & 2,71 & 1,55 \\
\hline $\mathrm{NO}_{3}^{-}$ & & 1,10 & 0,99 & 0,27 & 2,90 & 1,21 & 0,66 & 0,74 & 1,12 & 0,44 & 1,17 & 12,95 & 0,77 & 0,07 & 5,39 & 3,47 \\
\hline TDS & & 56,04 & 47,92 & 52,77 & 59,87 & 69,46 & 60,09 & 65,80 & 58,85 & 3,75 & 56,03 & 38,25 & 6,34 & 4,54 & 58,97 & 27,98 \\
\hline $\mathrm{S}^{+}$ & & 18.15 & 17.65 & 16.97 & 19.06 & 20.10 & 20.10 & 23.69 & 19.39 & 19.19 & 16.25 & 3.92 & 8.40 & 3.38 & 2.23 & 8.90 \\
\hline$S^{-}$ & & 39.66 & 31.84 & 36.45 & 42.79 & 46.86 & 42.05 & 44.75 & 40.63 & 38.53 & 39.37 & 10.72 & 28.19 & 9.18 & 7.94 & 22.32 \\
\hline${ }^{87} \mathrm{Sr} /{ }^{86} \mathrm{Sr}$ & & 0.719887 & 0.719519 & 0.720328 & - & - & 0.719198 & 0.720415 & - & - & - & - & - & - & 0.717791 & - \\
\hline
\end{tabular}

